\title{
STUDIES ON LMFBR SUBASSEMBLY BOUNDARY INTEGRITY
}

by

R. M. Crawford, W. W. Marr, A. Padilla, Jr., and P. Y. Wang

BASE TECHNOLOGY

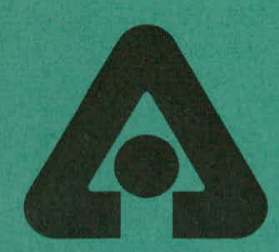

\section{MASTE}

ARGONNE NATIONAL LABORATORY, ARGONNE, ILLINOIS

Prepared for the U.S. ENERGY RESEARCH

AND DEVELOPMENT ADMINISTRATION

Division of Reactor Research and Development

under Contract W-31-109-Eng-38 


\section{DISCLAIMER}

This report was prepared as an account of work sponsored by an agency of the United States Government. Neither the United States Government nor any agency Thereof, nor any of their employees, makes any warranty, express or implied, or assumes any legal liability or responsibility for the accuracy, completeness, or usefulness of any information, apparatus, product, or process disclosed, or represents that its use would not infringe privately owned rights. Reference herein to any specific commercial product, process, or service by trade name, trademark, manufacturer, or otherwise does not necessarily constitute or imply its endorsement, recommendation, or favoring by the United States Government or any agency thereof. The views and opinions of authors expressed herein do not necessarily state or reflect those of the United States Government or any agency thereof. 


\section{DISCLAIMER}

Portions of this document may be illegible in electronic image products. Images are produced from the best available original document. 
The facilities of Argonne National Laboratory are owned by the United States Government. Under the terms of a contract (W-31-109-Eng-38) between the U. S. Energy Research and Development Administration, Argonne Universities Association and The University of Chicago, the University employs the staff and operates the Laboratory in accordance with policies and programs formulated, approved and reviewed by the Association.

\section{MEMBERS OF ARGONNE UNIVERSITIES ASSOCIATION}

The University of Arizona Carnegie-Mellon Univer sity

Case Western Reserve University

The University of Chicago

University of Cincinnati

IIlinois Institute of Technology

University of Illinois

Indiana University

Iowa State University

The University of Iowa
Kansas State University The University of Kansas Loyola University Marquette University Michigan State University The University of Michigan University of Minnesota University of Missouri Northwestern University University of Notre Dame
The Ohio State University Ohio University

The Pennsylvania State University

Purdue University

Saint Louis University

Southern Illinois University

The University of Texas at Austin

Washington University

Wayne State University

The University of Wisconsin

\section{NOTICE}

This report was prepared as an account of work sponsored by the United States Government. Neither the United States nor the United States Energy Research and Development Administration, nor any of their employees, nor any of their contractors, subcontractors, or their employees, makes any warranty, express or implied, or assumes any legal liability or responsibility for the accuracy, completeness or usefulness of any information, apparatus, product or process disclosed, or represents that its use would not infringe privately-owned rights. Mention of commercial products, their manufacturers, or their suppliers in this publication does not imply or connote approval or disapproval of the product by Argonne National Laboratory or the U. S. Energy Research and Development Administration.

Printed in the United States of America

Available from

National Technical Information Service

U. S. Department of Commerce 5285 Port Royal Road

Springfield, Virginia 22161

Price: Printed Copy $\$ 5.45 ;$ Microfiche $\$ 2.25$ 
ANL $-75-27$

ARGONNE NATIONAL LABORATORY

9700 South Cass Avenue

Argonne, I11inois 60439

\section{STUDIES ON LMFBR SUBASSEMBLY BOUNDARY INTEGRITY}

by

R. M. Crawford, * W. W. Marr, A. Padilla, Jr., ** and P. Y. Wang

Reactor Analysis and Safety Division

This report was prepared as an account of work sponsored by the United States Government. Neither the United States nor the United States Energy Research and Development Administration, nor any of their employees, nor any of their contractors, subcontractors, or their employees, makes any warranty, express or implied, or assumes any legal liability or responsibility for the accuracy, completeness or usefulness of any information, apparatus, product or process disclosed, or represents that its use would not infringe privately owned rights.

May 1975

* Now at Sargent \& Lundy, Chicago.

**Now at Hanford Engineering Development Laboratory, Richland, Wash. 
PREFACE

This is the second in a series of reports on the problem of fue1failure propagation. The principal objective of these reports is to review and analyze the potential for fuel-failure propagation in an LMFBR. This is being done to demonstrate LMFBR safety, even though there has been no evidence of fuel-failure propagation in currently operating reactors. The reports do not comment on current or.planned experiments or analytical programs, but review and summarize the results of such programs that have been completed to date.

In order to achieve this objective, a coherent argument is constructed using existing documented results whenever possible and providing results of additional, new analyses where there are gaps or serious discrepancies in the current arguments.

The subject of fuel-failure propagation in LMFBRs can be conveniently divided into three related areas:

(1) pin-to-pin failure propagation;

(2) subassembly-boundary integrity;

(3) subassembly-to-subassembly failure propagation.

The first area listed above has been discussed in a previous report. ${ }^{1}$ This report concentrates only on the second area, and presents a discussion of the initiating events and failure modes which may potentially lead to a breach of the subassembly-boundary integrity. A breach of the subassemblyboundary integrity in this report is defined as a condition in which the subassembly duct is ruptured or severely deformed.

It is concluded that a breach of the subassembly-boundary integrity is not expected to occur for the expected accident sources. However, a breach of the subassembly-boundary integrity might occur due to possible manufacturing defects of the duct or for some undefined failure mechanism. Even in these hypothetical cases, however, it is shown that a breach of the subassembly-boundary integrity does not lead to rapid fuel-pin failure propagation within the accident subassembly. This conclusion is supported by operating experience, experiments, and mechanistic analyses of failurepropagation phenomena presented in this report. report. 2

The third area of failure propagation will be discussed in another 
TABLE OF CONTENTS

$\underline{\text { Page }}$

ABSTRACT. ........................................ 9

I. INTRODUCTION AND PROBLEM DEFINITION................ 9

II. INITIAL FAULTS AND THEIR CONSEQUENCES $\ldots \ldots \ldots \ldots \ldots \ldots \ldots \ldots \ldots \ldots .10$

III. REACTOR OPERATING EXPERIENCE - THE FERMI INCIDENT .......... 14

IV. ANALYSIS OF POTENTIAL MODES OF FAILURE PROPAGATION......... 17

A. Mechanical Loading of Subassembly Duct.............. 18

B. Thermal Loading of the Subassembly Duct............. 21

1. Melting of the Subassembly Duct................ 21

2. Thermal Stress Analysis of Subassembly Duct......... 25

C. Coolant Flow Diversion....................... 31

1. Description of Mode1....................... 32

2. Analysis and Results..................... 34

3. Conclusions............................. 41

4. Assessment of Uncertainties................. 43

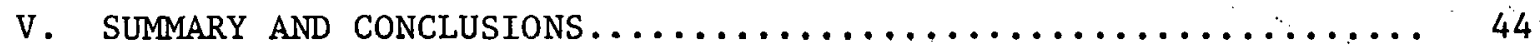

APPENDICES .................................... 45

A. The Fuel-Melting Incident in the Enrico Fermi Reactor....... 45

A. Description of the Incident.................... 45

B. Thermal-hydraulic Analysis of the Incident........... 45

b. Modification of COBRA-III Cumputer Code for

Leakage or Injection Flow....................... 48

A. Continuity Equation. ....................... 48

B. Energy Equation......................... 49

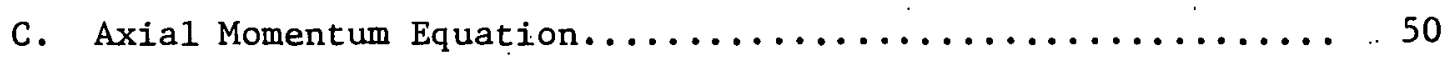

C. Material Properties for Thermal Stress Analysis

of a Subassembly Duct........................... 51

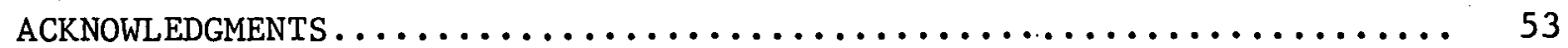

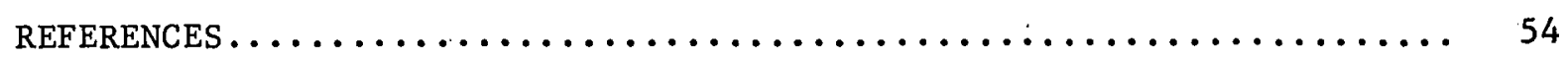


LIST OF FIGURES

No. Title

Page

1 Accident Progression Diagram AP.2: Fission-gas Release -

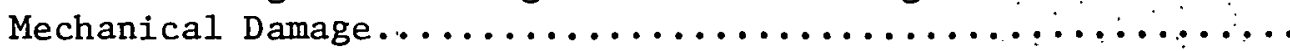

2 Accident Progression Diagram AP7: Release of a Smail

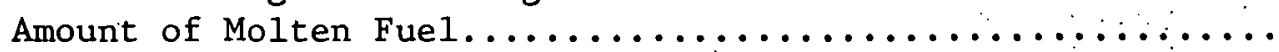

3 Accident Progression Diagram AP8: Expulsion of

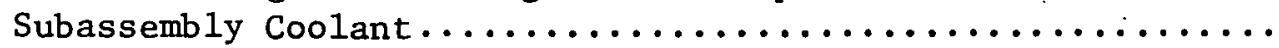

4 'l'hermal Analysis of Local Meltthrough of

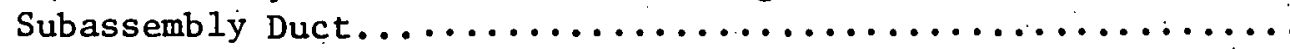

5 Heat-removal Capability of Accident and Adjacent Subassembly Ducts........................

Thermal Stress Analysis of Local Hotspot on

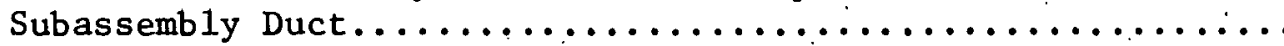

7 Temperature-gradient Limits for Elastic Behavior

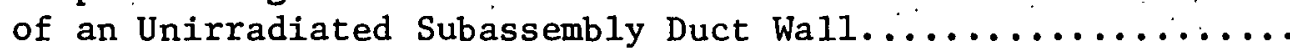

8 Variation of Inelastic Bending Moment with

Temperature Gradient..........................

9 Temperature Gradient for Plastic Behavior of an

Unirradiated Subassembly Duct Wall at $\mathrm{M} \simeq 0.99 \mathrm{M}_{\mathrm{FL}} \ldots \ldots \ldots \ldots$

10 Effect of Irradiation on Temperature Gradient for Elastic-Plastic Behavior of Subassembly Duct Wall...........

11 Temperature-gradient Limits for Elastic Behavior of a Type 316 Stainless . Steel Unirradiated

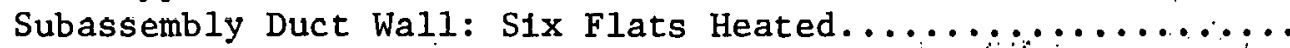

12 Temperature Gradient for Plastic Behavior of a Type 316 Stainless Steel Unirradiated Subassemily

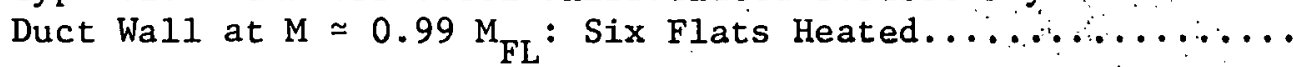

13 Temperature-gradient Limits for Elastic Behavior of a Type 316 Stainless Steel Unirradiated

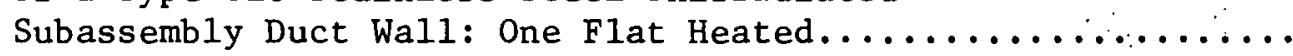

14 Temperature Gradient for Plastic Behavior of a Type 316 Stainlese Steel Unirradiated Subassembly Duct Wall at $\mathrm{M} \simeq 0.99 \mathrm{M}_{\mathrm{FL}}$ : One Flat Heated.......

15 Temperature Gradient for Elastic-Plastic

Behavior of an Unirradiated Cold-worked Type 316

Stainless Steel Subassembly Duct Wall................. 


\section{LIST OF FIGURES}

No.

$\underline{\text { Title }}$

$\underline{\text { Page }}$

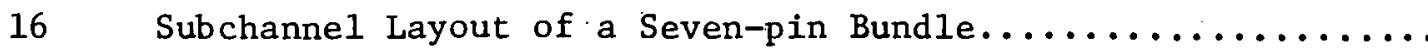

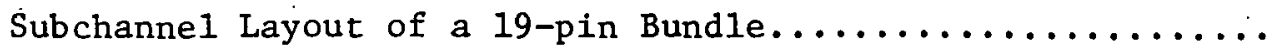

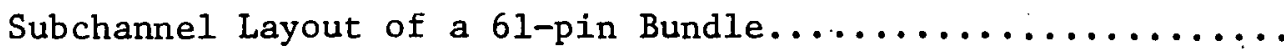

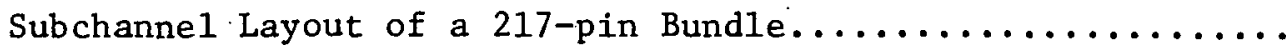

20 Local Flow Variation in the Subchannel Adjacent

to a 1-in. Rupture at Midcore for a Leakage

Flow Rate of $10.01 \mathrm{~b}_{\mathrm{m}} / \mathrm{sec}-\mathrm{ft}$ in Various Pin

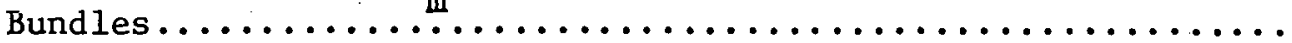

21 Local Temperature Variation in the Subchanne1

Adjacent to a 1-in. Rupture at Midcore for a

Leakage Flow Rate of $10.01 \mathrm{~b} / \mathrm{sec}-\mathrm{ft}$ in Various

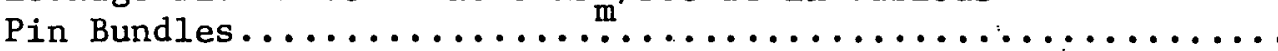

22 Variation of Maximum Temperature Increase with

Bundle Size for a Leakage Flow Rate of $10.01 \mathrm{~b}_{\mathrm{m}} / \mathrm{sec}-\mathrm{ft}$

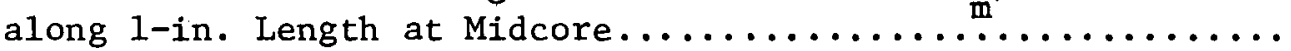

23 Local Flow Distribution in Subchannel 12 for Various

Leakage Flow Rates along 1-in. Length at Midcore in

the Seven-pin Bundle...........................

24 Local Temperature Increases in Subchannel 12 for

Várious Leakage Flow Rates along 1-in. Length in

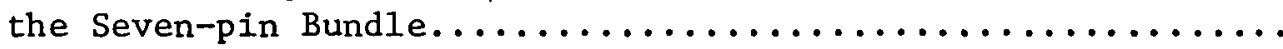

25 Variation of Maximum Decrease in Subchannel Flow

Rate with Bundle Size for a Leakage Flow Rate of

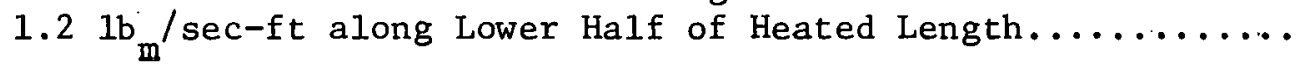

26 Variation of Maximum Temperature Increase with

Bundle Size for a Leakage Flow Rate of $1.2 \mathrm{lb} / \mathrm{sec}-\mathrm{ft}$

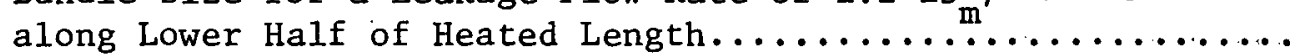

27 Flow Distribution in Subchannel 12 for Various

Leakage Flow Rates along Lower Half of Heated Length

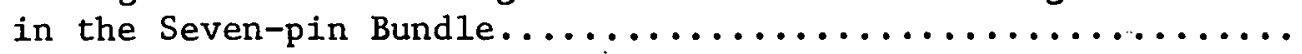

28 Temperature Distribution in Subchannel 12 for

Various Leakage Flow Rates along Lower Half of

Heated Length in the Seven-pin Bundle.

29 Effect of Leakage along Lower Half of Heated

Length on Flow Distribution across the 217-pin

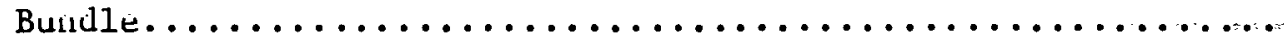




\section{LIST OF FIGURES}

No.

Title

$\underline{\text { Page }}$

30 Effect of Leakage along Lower Half of Heated Length on Temperature Distribution across the 217-pin

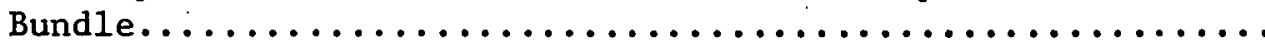

31 Flow Distribution in Subchannel 12 for Various Leakage Flows along the Entire Heated Length in the Seven-pin Bundle...........................

32 Temperature Distribution in subchannel 12 for Various Leakage Flows along the Entire Heated

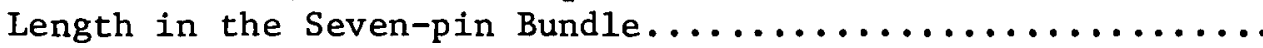

33 Axial Flow Variation in the Subchannel Adjacent to a 36-in. Rupture along the Entire Heated Length

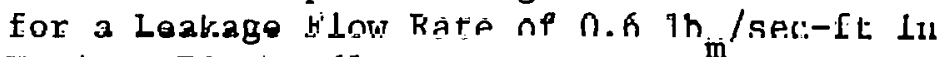

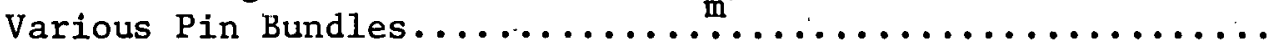

34 Axial Temperature Variation in the Subchannel Adjacent to a 36-in. Rupture along the Entire Heated Length for a Leakage Flow Rate of

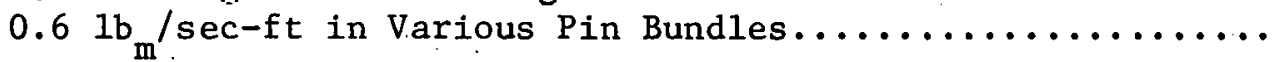

35 Variation of Maximum Decrease in Subchannel Flow

Rate with Bundle Size for a Leakage Flow Rate of

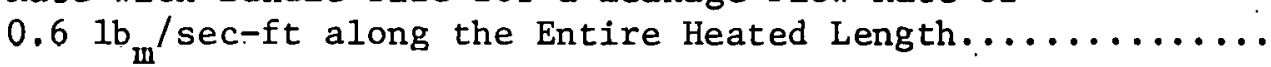

36 Variation of Maximum Temperature Increase with Bundle Size for a Leakage Flow Rate of

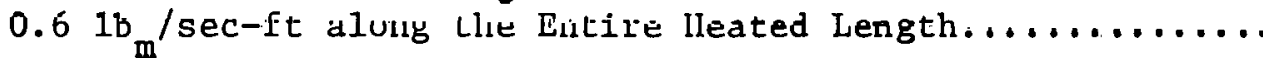

A.1 Fermi Reactor Loading on October $5,1966 \ldots \ldots \ldots \ldots \ldots \ldots \ldots$ 


\section{LIST OF TABLES}

No.

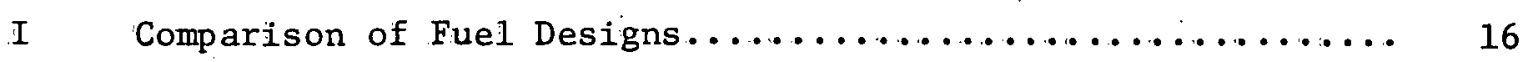

II Summary of Various Analyses of Mechanical Loading

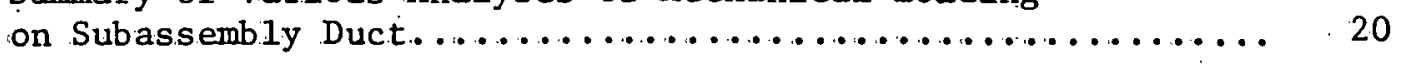

C.I Properties of Austenitic Steels 304 and $316 \ldots \ldots \ldots \ldots \ldots \ldots \ldots$........ 51

C.II Properties of Austenitic Steels at High Temperature......... 51

C.III Properties of Type-316 Cold-worked Stainless Steel after Irradiation (from BMI-1900)............. 52

C.IV Properties of Type-316 Cold-worked Stainless Steel after Irradiation (from GEAP-10062)............ 52 
THIS PAGE

\section{WAS INTENTIONALLY \\ LEFT BLANK}


STUDIES ON LMFBR SUBASSEMBLY BOUNDARY INTEGRITY

by

R. M. Crawford, W. W. Marr, A. Padilla, Jr., and P. Y. Wang

\begin{abstract}
In this report, initial faults and their associated failure-propagation modes are identified with the use of safety-assurance diagrams. To put these initial faults into perspective, reactor operating experience is reviewed with particular emphasis on the fuel-melting incident in the Fermi reactor. The ability of the subassembly duct to withstand a pressure-pulse loading is reviewed, including recent analyses of local MFCIs and subassembly-duct mechanical response. In addition, the thermal and mechanical response of the subassembly duct to contact with molten fuel is reviewed and extended; the thermal response (meltthrough) is discussed in the light of more recent analyses, and the mechanical-response behavior (therma1stress analysis) is extended into the plastic regime. The consequences of a localized failure of the subassembly duct is also analyzed.
\end{abstract}

\title{
I. INTRODUCTION AND PROBLEM DEFINITION
}

The purposes of this report are to review and summarize previous work, and to present the results of additional analysis of potential mechanisms for violating the integrity of the subassembly boundary. Even though a loss of subassembly-boundary integrity is not expected to occur for plausible initiating events, the potential consequences of such an incident has been investigated. In a previous report on local initiating events, ${ }^{1}$ various initial faults were reviewed and analyzed. On the basis. of current analyses and experiments, it was concluded that the potential propagation modes for fuel-pin failure resulting from postulated local initial faults were unlikely to occur and were inherently self-limiting. This report discusses the possible damage to the subassembly boundary. The duct integrity is shown not to be threatened by the expected range of initiating faults. However, several hypothetical accidents are postulated in order to determine the capability of the subassembly duct to withstand severe mechanical and thermal loads; in addition, the consequences of a localized failure of the subassembly duct are determined.

This report extends the earlier work of Judd and Boh $1^{3}$ to include the results of recent analyses and experiments. A considerable: amount of analysis has been performed previously on the response of the subassembly duct to pressure pulses and to contact with molten fuel. These analyses established conservative limits on the ability of the subassembly duct to withstand mechanical and thermal loads. In assessing various potential 
accident situations, Judd and Bohl concluded, based on pessimistic assumptions, that failure of the subassembly duct by pressure pulses due to a molten-fuel-coolant interaction (MFCI) or by melting due to contact with molten fuel could not be ruled out. These results and conclusions are reviewed and extended in this report.

In this report, initial faults and their associated failurepropagation modes are identified with the use of safety-assurance diagrams. To put these initial faults into perspective, reactor operating experience. is reviewed with particular emphasis on the fuel-melting incident in the Fermi reactor. The ability of the subassembly duct to withstand a pressure-pulse loading is reviewed, including recent analyses of local MFCIs and mechanical responses of subassembly ducts. In addition, the thermal and mechanical responses of the subassembly duct to contact with molten fuel is reviewed and extended; the thermal response (meltthrough) is discussed in the light of more recent analyses, and the mechanica1response behavior (thermal stress analysis) is extended into the plastic regime.

Finally, a locallzed fallure of the subassembly duct is postulated in order to analyze the thermal-hydraulic consequences of such a failure.

\section{INITIAL FAULTS AND THEIR CONSEQUENCES}

In a previous report on local initiating events, 1 various initial faults were identified by means of fault-tree and safety-assurance diagrams, and the potential consequences were assessed. These diagrams will not be discussed again in detail here, but the general conclusions of the assessment will be reviewed.

The initial faults were represented by three categories of accident source: (1) random fuel-pin failure, (2) fuel-p1n operatiun al overpower, and (3) debris in the primary coolant system. Fuel-pin damage and failure-propagation modes assoclated with these inftial faults were analyzed: (1) fission-gas release, (2) local MFCIs, and (3) local blockages in the fuel-pin bundle. Based on these analyses, as well as experimental results and reactor operating experience, it was concluded that fuel pin failure propagation is unlikely to occur and, if occurring, is inherently self-limiting. It is then not expected that severe mechanical or thermal loading of the duct will occur due to these local initiating events. Duct integrity is not threatened under these loads.

In order to determine the containment capability of the duct, the consequences of more severe hypothetical events, In which the integrity of the subassembly boundary may be violated, were analyzed. For example, a local MFCI or fuel debris adjacent to the subassembly wall might cause failure of the subassembly duct in a very localized region. The conditions under which localized failure of the subassembly duct can occur were analyzed, as well as the consequences of the localized failure. The results are presented in the following sections.

The failure-propagation modes associated with these postulated accident sources are presented in Figs. 1-3. Figure 1 shows the accldent 


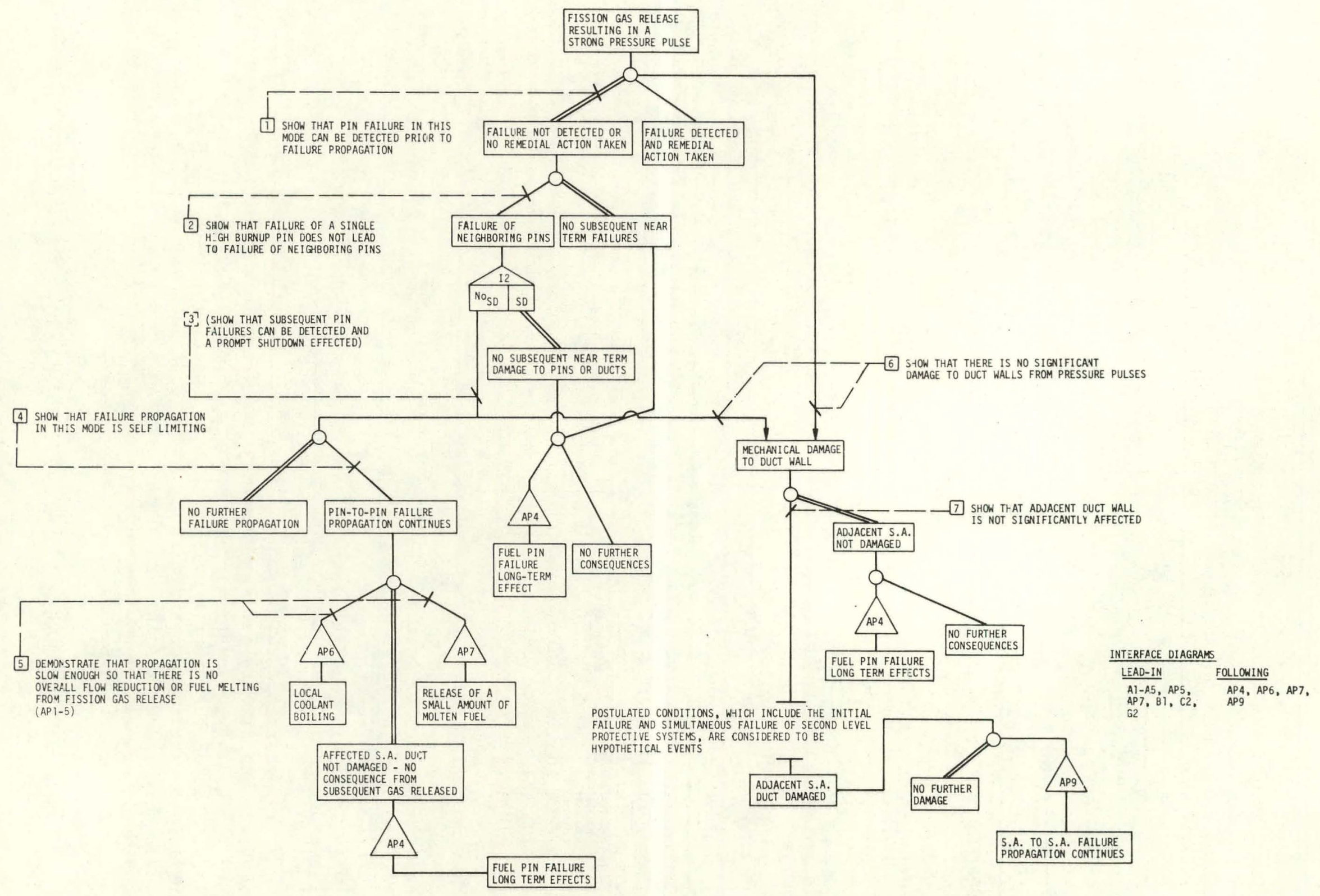

Fig. 1. Accident Progression Diagram AP2: Fission-gas Release - Mechanical Damage. (From Ref. 4). 


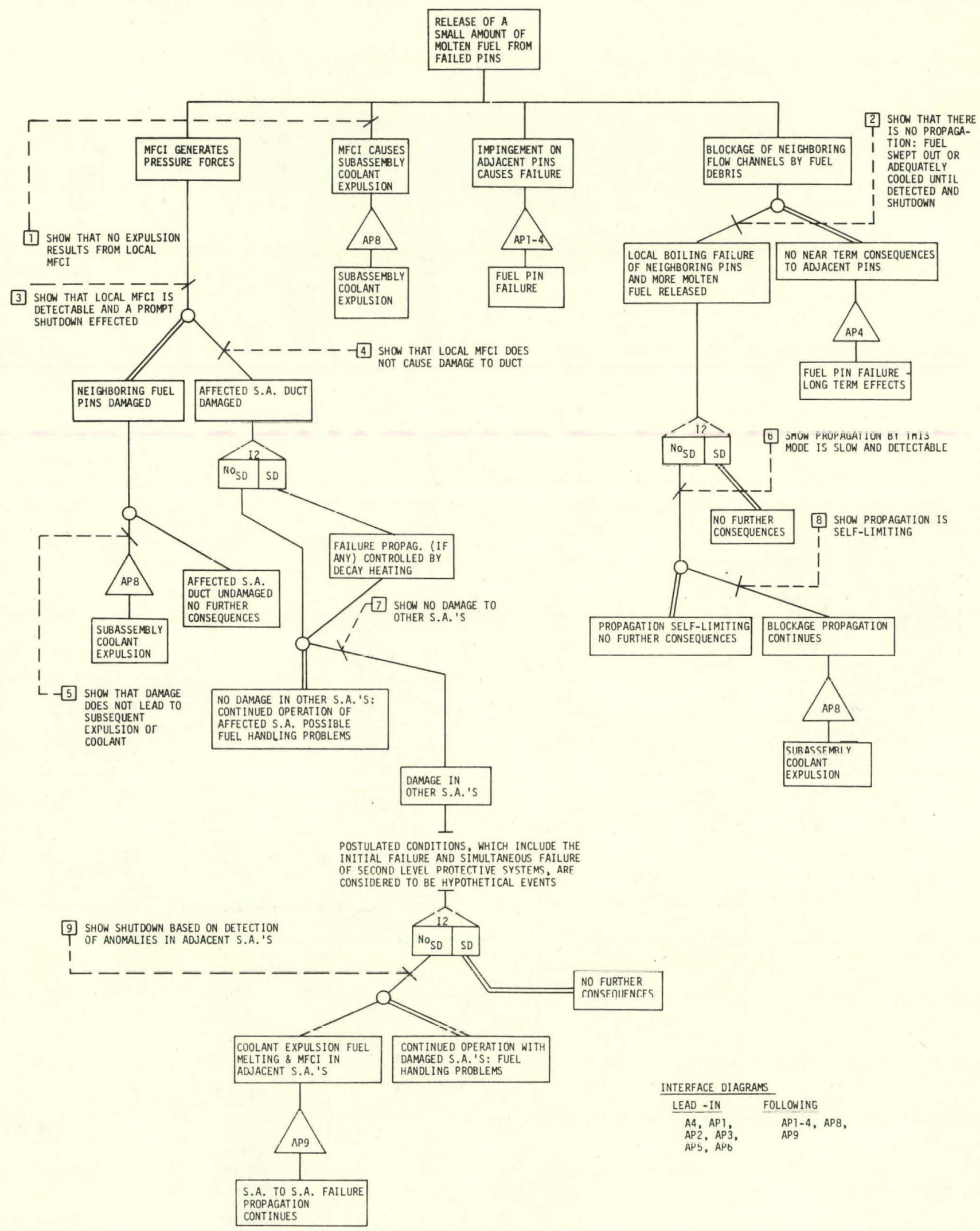

Fig. 2. Accident Progression Diagram AP7: Release of a SmaZl Amount of Molten Fuel. (From Ref. 4). 


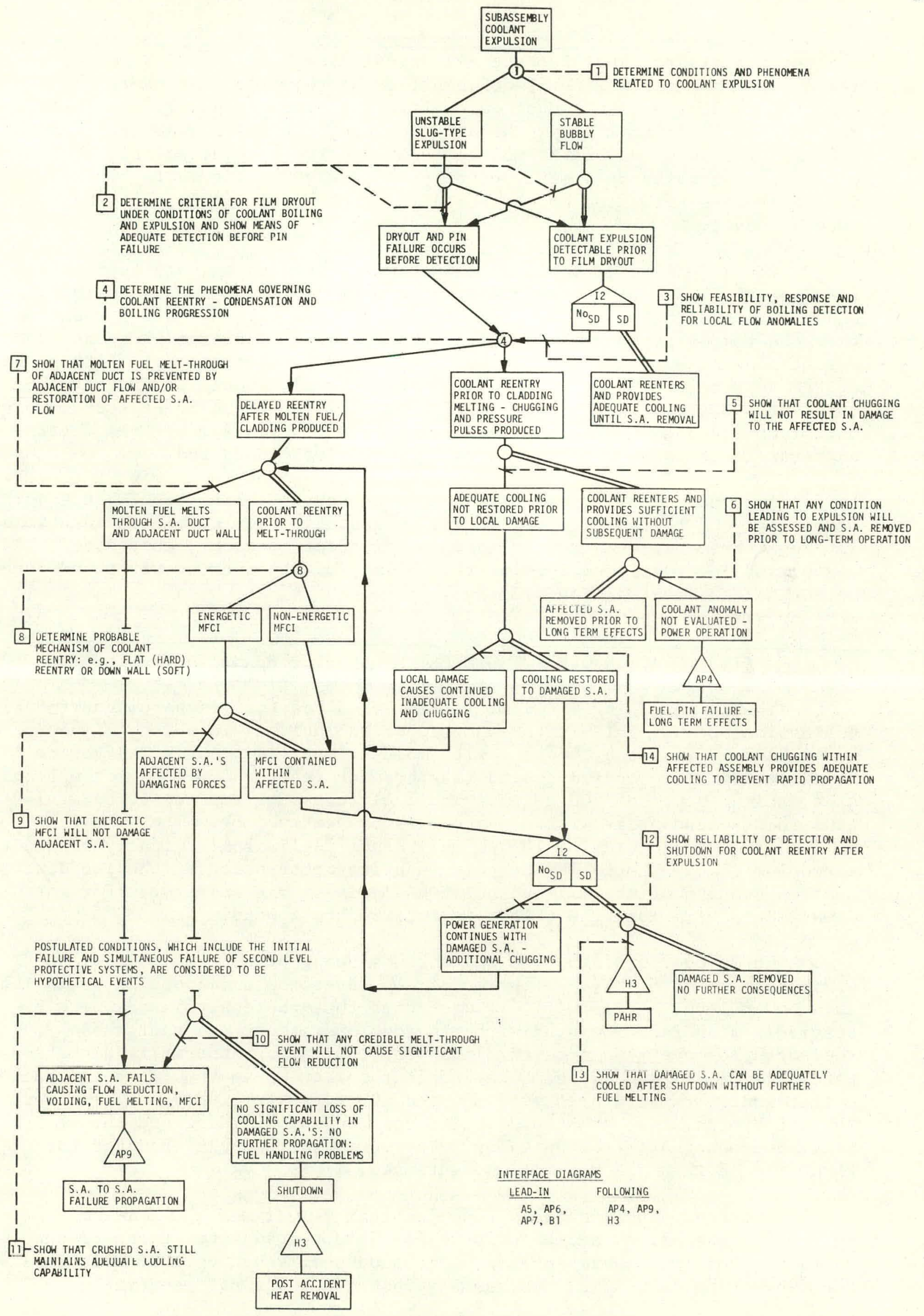

Fig. 3. Accident Progression Diagram AP8: Expulsion of Subassembly Coolant. (From Ref. 4). 
progression diagram AP2 ${ }^{4}$ for the mechanical damage from a fission-gas release; the applicable line of defense (LOD 6) requires that there be no significant damage to the duct walls from the pressure pulses caused by the gas release. Figure 2 shows the accident-progression diagram AP $7^{4}$ for the release of a small amount of molten fuel, and LOD 4 requires that the pressures generated by a MFCI do not cause damage to the duct. These two diagrams present the two major sources of mechanical loading for the subassembly duct.

The major source of thermal loading of the subassembly duct arises from the sequence of events following expulsion of subassembly coolant, as shown on the accident-progression diagram $\mathrm{AP}^{4}$ in Fig. 3. LOD 5 requires that the temperatures and pressures associated with coolant chugging do not result in damage to the subassembly duct. LOD 7 requires that meltthrough of the duct be prevented by adequate heat-removal capability in the adjacent subassembly or by restoration of flow in the accident subassemb1y. More local sources of thermal loading, such as a blockage by fuel debirs adjacent to the subassembly duct wall, were also considered.

In conclusion, hypothetical accident sources which result in severe mechanical and thermal loading of the subassembly duct have been identified. Although these accident sources are not expected to occur, they are postulated in order to determine the ability of the duct to withstand severe mechanical and thermal loads.

\section{REACTOR OPERATING EXPERIENCE - THE FERMI INCIDENT}

The fuel-melting incident in the Fermi reactor ${ }^{5}$ is pertinent to this discussion because this is the only reported incident in which failure of the subassembly duct by contact with molten fuel did occur. The Enrico Fermi reactor is a sodium-cooled fast breeder reactor designed for operation at a maximum power of $200 \mathrm{MW}(\mathrm{t})$. The fuel subassemblies consisted of 144 pins in a square array within a square subassembly duct. The fuel pins consisted of enriched uranium-10 w/o molybdenum fuel metallurgically bonded to zirconium clad. The following gives a brief description of the incident and the results of thermal-hydraulic analysis of the incident. For more detailed information, the reader is referred to Appendix A.

On October 5, 1966, the reactor was being brought up to a planned maximum power of $67 \mathrm{MW}(t)$ with two of its three coolant loops in operation. At a power level of $31 \mathrm{MW}(t)$, it was noted that the control rods were excessively withdrawn compared with previous operation, and that the thermocouples over two subassemblies were indicating abnormally high temperatures of 715 and $695^{\circ} \mathrm{F}$ at the coolant outlet, when the inlet and bulk outlet sodium temperatures were 535 and $600^{\circ} \mathrm{F}$, respectively. Alarms were set off by radiation detectors in the containment building and the fission-product-detector building. The power was manually reduced to $26 \mathrm{MW}(\mathrm{t})$ and then the reactor was scrammed.

Subsequent examinations revealed that fuel melting had occurred in two subassemblies, and holes were found in the adjacent faces of the ducts of these two subassemblies. One subassembly had another hole in its duct bordering on a third subassembly whose duct was not penetrated. 
Nothing was found in any of the subassemblies that could have caused the fuel melting, but two of the six zirconium segments originally installed on a conical flow guide were found loose in the reactor inlet plenum. It was concluded that these zirconium segments were the only possible source which could have caused the fuel-melting incident.

A thermal-hydraulic analysis ${ }^{6}$ indicated that a blockage at the subassembly inlet by a zirconium segment would reduce the flow to approximately 0 to $3 \%$ of nominal in the two subassemblies in which fuel melting had occurred. The third subassembly mentioned above had its flow reduced to somewhat less than $10 \%$ nominal.

As the reactor power level was increased, it is postulated that a sodium-vapor bubble. filled the central region of the two adjacent blocked subassemblies where the temperatures were above the boiling point of sodium. Within this region, the fuel. melted and flowed to the sides and bottom of the bubble, then froze when coming into contact with liquid sodium. Eventually, enough fuel slumped to form plugs which penetrated the subassembly ducts of the two blocked subassemblies.

Although the inlet flow may have been blocked by the zirconium segment and the fuel plugs, sodium could have entered the two blocked subassemblies through the holes in their ducts and provided appreciable convective cooling by two-phase sodium flow through the vapor-bubble region. The sodium between the subassemblies is nominally stagnant, but some leakage flow into this region exists in the inlet nozzles. The absence of even more melting of the ducts of the blocked subassemblies than actually occurred is attributed to cooling from thermally induced natural circulation of the sodium in the gap between the blocked subassemblies.

It is significant that in the Fermi incident failure propagation to adjacent normal subassemblies or even to the adjacent partially-blocked subassembly did not occur. Also, the role of natural circulation of the sodium in the gap between the blocked subassemblies in mitigating the amount of duct melting was concluded to be a very important effect. However, the conclusions of the Fermi fuel-melting incident cannot be applied directly to postulated LMFBR accident situations because the Fermi fuel-pin and cubassembly design and materials are quite different from those of current. LMFBR designs. Table I summarizes some of these similarities and differences between Fermi and LMFBRs (the FFTF design ${ }^{7}$ is used as an example of current LMFBR design).

From Table I, it is obvious that although the Fermi reactor is of the sodium-cooled fast-breeder type, there are substantial differences with current LMFBR design. With respect to subassembly failure and its propagation, one of the most.important differences is the sequence of events in fuel melting process and the behavior of the molten fuel itself. For LMFBR fuel pins, the melting point of the mixed-oxide fuel is much higher than that of the stainless steel cladding. When the fuel pins are blanketed by sodium vapor, the cladding would be expected to melt and slump downward much before fuel melting begins.

For Fermi fuel pins, the melting point of the metal-alloy fuel $\left(2100^{\circ} \mathrm{F}\right)$ is much lower than that of the zirconium cladding $\left(3340^{\circ} \mathrm{F}\right)$. In 
Table I. Comparison of Fuel Designs

Fue1-pin Design

Pin OD, in.

Fuel length, in.

Cladding material

Cladding thickness, in.

Fuel material

Initial fuel-cladding

gap, in.

Type of spacers

Pin-to-pin spacing, in.

Subassembly Design

Number of pins

Duct configuration

Flat-to-flat oD, in.

Duct material

Duct-wall thichness, ill.

Gap between subassemblies, in.

Coolant bulk inlet/outlet temperatures, ${ }^{\circ} \mathrm{F}$ $\underline{\text { Fermi }}$

LMFBR

0.23

0.158

36

zirconium

Type 316 SS

0.005

0.015

U-10 w/o Mo

$\mathrm{PuO}_{2}-\mathrm{UO}_{2}$

0

0.003

metallurgically

bonded grids

0.041

(square pitch)

(triangular pitch)
140

square

2.646

Type 347 SS

0.096

0.047

545/670 [100 MW $(t)$ operation]
0.056

spiral wire wraps

Fermi

LMFBR

217

hexagona1

4.575

Type 316 SS

0.12

0.14

the Fermi fuel-melting incident, it was concluded that cladding failure occurred when the fuel temperatures were between 2100 and $2600^{\circ} \mathrm{F}$. The dissolution rate of zirconium by molten uranium increases rapidly with temperature, and the cladding would be expected to be completely dissolved by the fuel in about $40 \mathrm{sec}$ at $2300^{\circ} \mathrm{F}$ or $4 \mathrm{sec}$ at $2550^{\circ} \mathrm{F}$. Postincident examination of the blocked subassemblies showed complete fuel-pin melting in the region of the sodium-vapor bubble with little evidence of intact zirconium cladding.

The behavior of the molten fuel in contact with the stainless steel duct wall is quite different for the Fermi metal-alloy fuel versus the LMFBR mixed-oxide fuel. Previous analyses ${ }^{8,9}$ of molten LMFBR mixed-oxide fuel suddenly contacting the duct wall indicated that the duct wall of the accident subassembly would not melt through until. 3 to $10 \mathrm{sec}$, even though there is continual contact between fuel and the steel wall cooled by the intersubassembly sodium. In fact, solid mixed-oxide fuel may tend to form a protective layer of low thermal conductivity next to the duct wall. 
Since the melting point of the Fermi metal-alloy fuel is below that of the stainless steel duct, melting of the duct will not occur until the fuel is substantially above its melting point. However, uranium forms a low-melting eutectic with iron at $1337^{\circ} \mathrm{F}$. The penetration rate is relatively slow at temperatures between 1337 and $1960^{\circ} \mathrm{F}(<0.00002 \mathrm{in./sec})$, but is much more rapid $(0.0026$ to $0.015 \mathrm{in} . / \mathrm{sec})$ at temperatures above $1960^{\circ} \mathrm{F}$. Thus, the molten metal-alloy fuel could have penetrated the stainless steel duct wall in about $13 \mathrm{sec}$, even if it was below the melting point of the duct wall.

The amount of molten fuel which can transfer heat to the duct wall may be much different for the Fermi metal-alloy fuel than for LMFBR mixedoxide fuel. Previous analyses 8,9 for LMFBR mixed-oxide fuel have used the concept of a maximum nonbolling fuel layer next to the duct wall. The thermal conductivity of the metal-alloy fuel is larger by about an order of magnitude than that of the mixed-oxide fuel, and therefore much more metalalloy fuel can be in contact with the duct wall if the same criterion of a maximum nonboiling thickncse is assumed. This would mean higher heat fluxes might be transferred to the duct wall by the metal-alloy fuel.

It would be difficult to show that LMFBR mixed-oxide fuel is inherently safer than the Fermi metal-alloy fuel. However, one fact might make the possibility of loss of subassembly-boundary integrity and subassemblyto-subassembly failure propagation more likely in the case of metal-alloy fuel: eventual penetration of the stainless steel duct wall can occur at temperatures as low as $1337^{\circ} \mathrm{F}$, the lower limit for forming the U-Fe eutectic.

The Fermi incident demonstrated the need to design against large subassembly-inlet blockages, and all subsequent reactor designs have carefully evaluated the potential for a Fermi-type blockage. For example, in the case of FTR, the design of the inlet plenum and of the subassemblyinlet nozzles minimizes the possibility of a complete or nearly complete blockage of flow to the subassembly. Therefore, a complete subassembly inlet blockagc is not considered in this report.

\section{ANALYSIS OF POTENTIAL MODES OF FAILURE PROPAGATION}

From the previous discussion of the initiating faults, two major areas of concern in determining the integrity of the subassembly boundary are the response of the duct to mechanical and thermal loads.

Much analysis has already been done in order to predict the mechanical response of the subassembly duct to pressure pulses and the thermal. response when the subassembly duct is contacted by molten fuel. Some of these previous studies are reviewed and summarized in this section, and the results of more recent studies are presented. The thermal stress analysis of a subassembly duct subjected to severe temperature gradients is chosen for further analysis, since all previous studies ignored the important aspect of asymmetric elastic-plastic behavior of the duct. A preliminary model is developed to predict whether the duct would be expected to fail from thermal stresses before it begins to melt. 
Although expected mechanical and thermal loads would not cause the subassembly duct to fail, certain hypothetical dynamic loads are postulated which might cause a localized rupture. The effect of such a localized rupture on the coolant flow and temperature distribution in the accident subassembly is parametrically investigated.

\section{A. Mechanical Loading of Subassembly Duct}

The response of the subassembly duct to an internal pressure pulse has been the subject of many analytical $3,8,10,11,17$ and some experimental investigations.12,13 As noted in Sect. II on initiating faults, internal pressure pulses may arise from the sudden release of fission gases following fuel-pin failure, from local thermal interactions of the coolant with molten materials, or from sodium hammer on reentry of a sodium slug following sodium voiding and expulsion.

Although some LMFBR fuel pins are designed to accommodate pressures greater than 1000 psia in their gas plenums, the maximum pressure for initial operation of the FFTF reactor is expected to be about 550 psia. The pressuce pulse due Lo a local MFCI has been discussed. 1 for realistic estimates of local MFCIs, the pressures generated may be of the order of $10 \mathrm{~atm} .{ }^{14}$ In order to provide a conservative estimate of the maximum dynamic pressures associated with a local MFCI, a hypothetical case was selected for testing the integrity of the subassembly duct. This hypothetical pressure pulse had an amplitude of 80 atm with a rise time of $1 \mathrm{msec}$ and a total pulse width of $4 \mathrm{msec}$. The energy associated with the pressure pulse was slightly less than $100 \mathrm{~J}$ ( $268 \mathrm{in.}-1 \mathrm{~b}_{\mathrm{f}} / \mathrm{in}$. for an interaction zone length of 13 in.).

Several previous analytical studiec have resulted in an energy criterion for subassembly-duct failure based upon a static simulation of the pressure pulse loading. The pressure pulse was assumed to have the characteristics of a shockwave (high pressure and brief duration) which impacted the subassembly duct and resulted in an impulsive load. The energy imparted to the subassembly duct was absorbed by the duct as it deformed, and it was assumed that the deformation, energy absorbed, stresses, and strains caused by the shock pulse loading could be predicted by an equivalent static pressure.

Using the above approach, Cole (McWethy et a1.) 10 concluded that an energy density of $18.8 \mathrm{in.}-1 \mathrm{~b}_{\mathrm{f}} / \mathrm{in} .^{2}$ (300 in. $-1 \mathrm{~b} / \mathrm{in}$. for an FFTF duct) would offer little threat to the integrity of a duct at $1000^{\circ} \mathrm{F}$ in early life, although the calculated strain was $4.8 \%$. Near the end of life, with a higher yield strength and lower ductility, he calculated a strain of $2 \%$ and concluded that the duct would still have a good chance of survival.

The approach adopted by Coffield and Wattelet ${ }^{8}$ was similar to that of cole. They used the FEATS finite-element computer code to estimate how much energy the duct could absorb before reaching its rupture strain and concluded that an FFTF duct at $1000^{\circ} \mathrm{F}$ could absorb $212 \mathrm{in} .-1 \mathrm{~b}_{\mathrm{f}} / \mathrm{in}$. before reaching its assumed rupture strain of about $2.5 \%$.

Judd $^{3}$ stated that the use of the energy available in the pressure pulse to determine duct failure was misleading and probably resulted in 
pulse energies which are alarmingly low. Instead of an energy criterion, he stated that the response of the subassembly duct should be determined by the pressure-time history of the pulse. For "slow" pulses, which he estimated to be those with rise times greater than about $1 \mathrm{msec}$, he concluded that the loading could be considered as quasi-static and that the effect could be determined by a static analysis using the peak pressure alone. He then calculated that an irradiated FFTF subassembly duct at $1000^{\circ} \mathrm{F}$ would fail for a "slow" pressure pulse with a peak of about 800 psi.

For more rapid pulses, Judd considered various triangular pulses and found that the peak pressure required for failure increases as the pulse width decreases. For example, a peak pressure of 1390 psi was required for failure when the pulse width was $0.5 \mathrm{msec}$ and the required peak pressure for failure increased to $2190 \mathrm{psi}$ for a pulse width of $0.1 \mathrm{msec}$.

McCalltl recently analyzed the response of an irradiated FFTF subassembly duct using the ANSYS finite-element computer code. He assumed that the pressure pulse was "slow" enough to justify use of a uniform static pressure loading and determined that a duct at $1000^{\circ} \mathrm{F}$ may fail for a pressure pulse with a peak of 555 psi. When the additional strength of the surrounding subassemblies was taken into account, where tight coupling of the ducts by the interassembly gap sodium was assumed, he found that the peak pressure required for duct rupture was increased to 700 psi.

More recent, Kennedy, 15 using the STRAW finite-element computer code, identified the need for dynamic, rather than static, analyses. Using a triangular pressure pulse with varying rise times, he found that rise times of $1 \mathrm{msec}$ and larger yielded results which were nearly static, and that rise times of $0.5 \mathrm{msec}$ and smaller yielded results which were definitely dynamic for a freely standing isolated hexagonal duct. 16 When he accounted for the compressible sodium between the surrounding subassemblies, he found that even pressure pulses of $1-\mathrm{msec}$ rise times would have to be treated dynamically. For a triangular pressure pulse with a rise time of $1 \mathrm{msec}$ and a total width of $4 \mathrm{msec}$, Kennedy predicted that a pressure of $750 \mathrm{psi}$ was required for failure of a freely standing irradiated FFTF duct at $1000^{\circ} \mathrm{F} .17$ When the compressible sodium in the interassembly gaps and in the adjacent subassemblies was taken into account, a peak pressure of 1200 psi did nut tesult in duct failure, but the calculated etrain was $1.00 \% .17$ It is expected that the ability of the subassembly duct to withstand pressure pulses will be further increased when the resistance to crushing of the fuel-pin bundles inside the adjacent subassemblies is taken into account.

The hypothetical local MFCI selected for this study can now be put into proper perspective in view of the above analytical studies, which are summarized in Table II. When the integrated energy in the pressure pulse is taken over the assumed 9-in.-long MFCI region, the maximum energy deposited in the subassembly duct is about 91 in. $-1 b_{f} / i n$. This is lower by a factor of about 3 than the energy required for duct failure suggested by Cole ${ }^{10}$ and Coffield and Wattelet. ${ }^{8}$ If the predicted pressure-time history of the hypothetical local MFCI is considered, the results of Kennedy ${ }^{17}$ also indicate that the subassembly duct will not fail. Further improvements in his model are expected to show an increase in the margin of safety for duct integrity. 
Tajle II. Summary of Varicus Analyses of Mechanical Lcacing on Subassembly Duct.

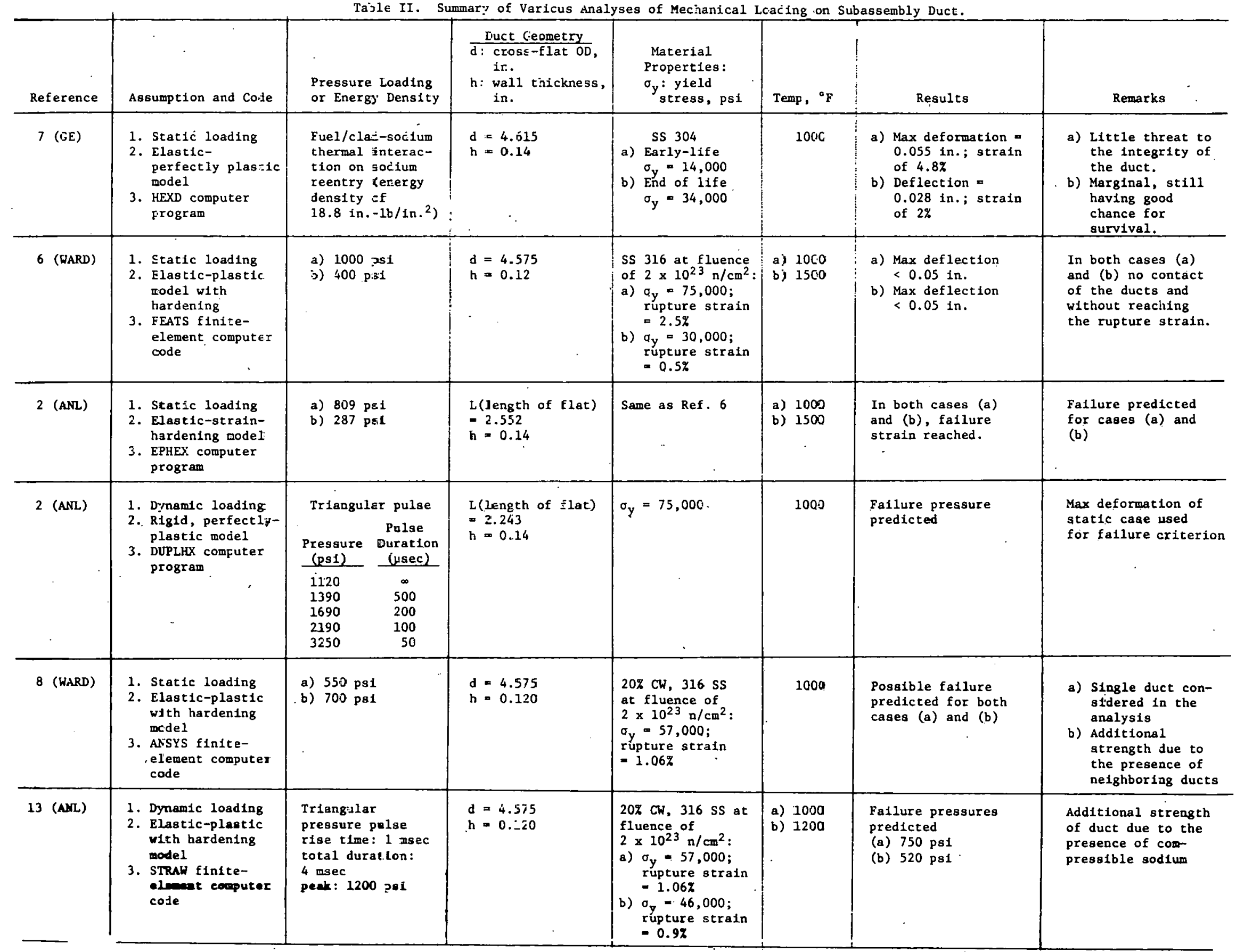


The energy associated with this hypothetical local MFCI can also be compared with the experimental data available. PFR-type subassembly ducts were subjected to internal chemical (PETN) explosions, and it was found that $0.5 \mathrm{lb}$ of PETN caused little structural damage, whereas $2 \mathrm{lb}$ of PETN caused substantial damage. 12 If we take an energy equivalence of $1 \mathrm{MW}-\mathrm{sec}\left(10^{6} \mathrm{~J}\right)$ per $0.5 \mathrm{lb}$ of PETN, the energy in the hypothetical MFCI pressure pulse is lower than the energy required to fail the PFR subassembly duct by a factor of $10^{4}$.

EBR-II subassembly ducts were also subjected to internal chemical (Bullseye Pistol Power) explosions by Boers.13 By use of 125-mg explosive charges, which were reported to have an energy release of less than $0.15 \mathrm{Btu}(158 \mathrm{~J})$, a maximum deformation of 0.02 in. was reported, but no duct failures occurred. The EBR-II duct thickness of 0.040 in. is substantially lower than the FFTF value of $0.120 \mathrm{in}$, and the energy release of $158 \mathrm{~J}$ is also substantially higher than the energy in the hypothetical MFCI pressure pulse, again suggesting that the hypothetical MFCI pressure pulse might not cause failure of the FFTF subassembly duct. Unfortunately, the British PFR results and the EBR-II subassembly tests may not be directly applicable for at least two reasons: (1) the magnitude and shape of the pressure pulse from a chemical explosion may be quite different from the MFCI pressure pulse even though there is an attempt to shape the pulse, and (2) ductile materials (unirradiated mild steel) were used in these experiments. However, the difference of four orders of magnitude in the energy required for duct failure is indicative of the very small amount of energy which may result from a hypothetical MFCI pressure pulse.

Since the maximum possible pressure from a sudden fission-gas release (550 psia) is lower than the pressures postulated in the foregoing analyses and experienced experimentally, it is concluded that failure of the subassembly duct due to pressure pulses is not expected. Further dynamic elastic-plastic analysis is required in order to demonstrate adequately the margin of safety.

\section{B. Thermal Loading of the Subassembly Duct}

\section{Melting of the Subassemb1y Duct}

If the subassembly duct is to melt, it must be contacted by hot fuel above the melting point of stainless steel. Since the presence of liquid sodium would prevent fuel from attaining such high temperatures, such a situation could exist only after sodium voiding has occurred and the subassembly remains voided for a few seconds. In a previous report on local initiating events, 1 it was shown that local coolant boiling due to a local blockage or a local MFCI is not expected to propagate to the entire subassembly and that restoration of the coolant flow would be expected even if only on an intermittent basis. Therefore, it is not expected that any local initiating event in the fuel subassembly will lead to whole subassembly voiding and subsequent meltdown. An initiating fault which could lead to subassembly coolant expulsion is a large subassembly blockage, but this type of occurrence is unlikely for the FFTF subassembly because the inlet plenum and subassembly inlet nozzle are specifically designed to prevent this situation, as discussed previously in Sect. III. Therefore, a complete subassembly inlet blockage is considered to be very unlikely. 
Therefore, since no likely mechanism has been identified yet which results in large amounts of hot fuel sufficient to cause duct melting, the existence of molten fuel in the absence of liquid sodium is postulated solely in order to predict the response of the subassembly duct under a severe loading situation. The hypothetical situation where solid and molten fuel is deposited on the inside of the subassembly duct has been analyzed frequently. McWethy et al., 18 considered the case in which a $0.3-$ in.-thick layer of molten fue 1 initially at $5000^{\circ} \mathrm{F}$ is placed against the duct wall initially at $1000^{\circ} \mathrm{F}$. The sodium gap between subassemblies was neglected, and the adjacent subassembly duct was assumed to be in contact with the accident subassembly duct. For full-power conditions, the accident subassembly duct was completely melted through in about $15 \mathrm{sec}$ when the calculation was terminated, and it was apparent that substantial melting of the adjacent subassembly duct would also occur.

Cofficld and Wattclet ${ }^{8}$ limited the amount of fuel in contact with the duct by considering only that fuel thickness which is below the assumed fuel boiling point of $6100^{\circ} \mathrm{F}$. For realistic ranges of the parameters involved, it was found that the maxdmum nonboiling fuel thickness at peak power conditions would be limited to 0.1 in. or less. At $5 \%$ decay power, the maximum nonboiling thickness was about 4.5 times the full-power value. The results indicated that at full power molten fuel in contact with the duct wall would result in boiling of stagnant sodium in the interassembly gap in about $4 \mathrm{sec}$. If it is assumed that sodium boiling results in vapor blanketing of the outside surface of the duct, then complete melting of the accident subassembly duct would occur in a matter of a few more seconds. In the shutdown case ( $5 \%$ decay power), it was found that the molten fuel would not completely melt through the accident subassembly duct if it were deposited near the inlet region.

Keaten ${ }^{19}$ considered the additional effects of solid-fuel breakaway and molten-steel drainage. Since the sodium velocity in the interassembly gap was assumed to be $2.7 \%$ of the normal subassembly coolant velocity, an equilibrium condition was reached in which solidified fuel was in contact with a partially molten duct. Due to deformation of the duct, the solidified fuel was assumed to break off and the molten steel to drain away every 2 or $3 \mathrm{sec}$, thus allowing fresh molten fuel to come into contact with the solid duct again. The duct-wail thickness was reduced approximatcly $20 \%$ per cycle, and duct failure was estimated to occur after: about 3 cycles. The total meltthrough time was estimated to be approximately $15-20 \mathrm{sec}$.

Pedersen ${ }^{9}$ analyzed the effect of relatively small amounts' of molten fuel (less than $210 \%$ of the fuel inventory of a single fuel pin) on the subassembly duct. Figure 4 shows the geometry involved and some of the results obtained. If vapor blanketing occurs in the interassembly gap immediately following the onset of boiling of the stagnant sodium at $943^{\circ} \mathrm{C}$ $\left(1730^{\circ} \mathrm{F}\right)$, the time of complete melting of the accident subassembly duct was $2.9 \mathrm{sec}$. This meltthrough time is lower by a factor of 2 to 3 than the values obtained by previous investigators, and it is primarily due to the assumptions of higher initial temperature distribution of the duct wall and higher heat flux ( $\sim 2$ times higher than that McWethy used). For diameters of the $0.1-i n .-t h i c k \mathrm{UO}_{2}$ disc exceeding about 1 in., the meltthrough times at the centerline were no longer affected by the disc diameter. 

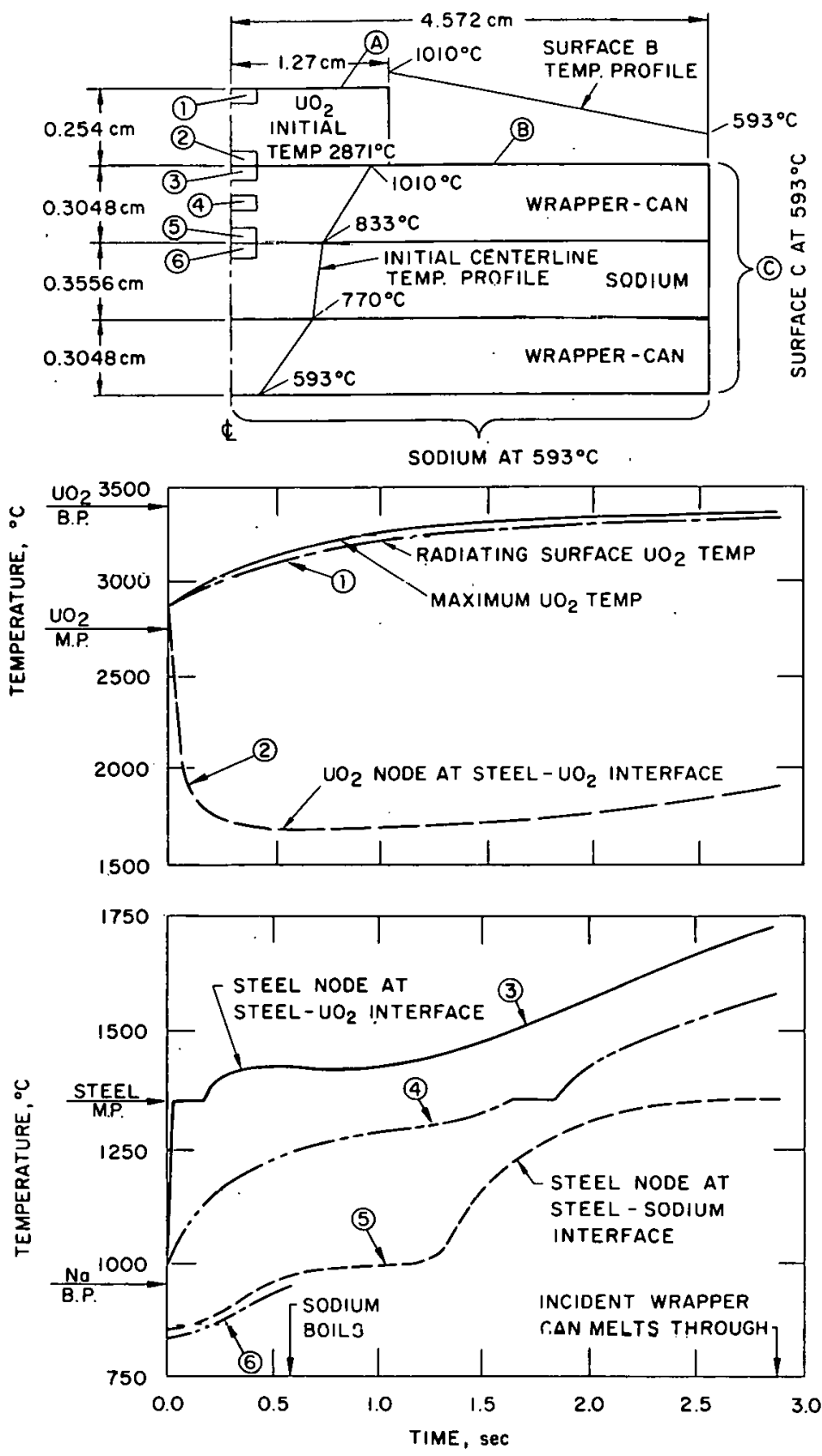

Fig. 4. Thermal Analysis of Local Meltthrough of Subassembly Duct. ANL Neg. NU. 900-181?.
Although cracking and/or breaking away of the solidified $\mathrm{UO}_{2}$ crust was not considered, it was found that drainage of molten steel at the $\mathrm{UO}_{2}-$ steel interface reduced the meltthrough time to $2.5 \mathrm{sec}$. When the $\mathrm{UO}_{2}$ disc diameter was reduced to $1 / 2$ in., the meltthrough time increased to $4.4 \mathrm{sec}$. For this latter case, increasing the sodium boiling temperature from 943 to $1010^{\circ} \mathrm{C}$ prevented complete meltthrough of the accident subassembly duct. However, the effect of natural convection of the sodium in the interassembly gap in preventing complete meltthrough was not investigated.

From the foregoing discussion, the major variables and/or parameters which affect the ability of the subassembly duct to withstand melting when contacted by molten fuel are: (a) the amount of molten fuel and its heat-generation rate (ful1-power versus shutdown condition), (b) the thermal resistances at the fuel-luct wall interface (cracking and breakaway of the solidified fuel crust and drainage of the molten steel), and (c) heattransfer mechanisms (natural or forced convection in the Linterassembly gap sodium.

Results of the previous studies are put in perspective in Fig. 5, which compares the steady-state heat-removal capability of the accident and adjacent subassembly ducts with different heat sources. The parameters are for steady-state conditions only and do not account for the energy associated with fuel solidification; in addition, the interassembly gap sodium is neglected. This steady-state condition corresponds to the situation in which molten fuel builds up gradually to a certain thickness, whereas 


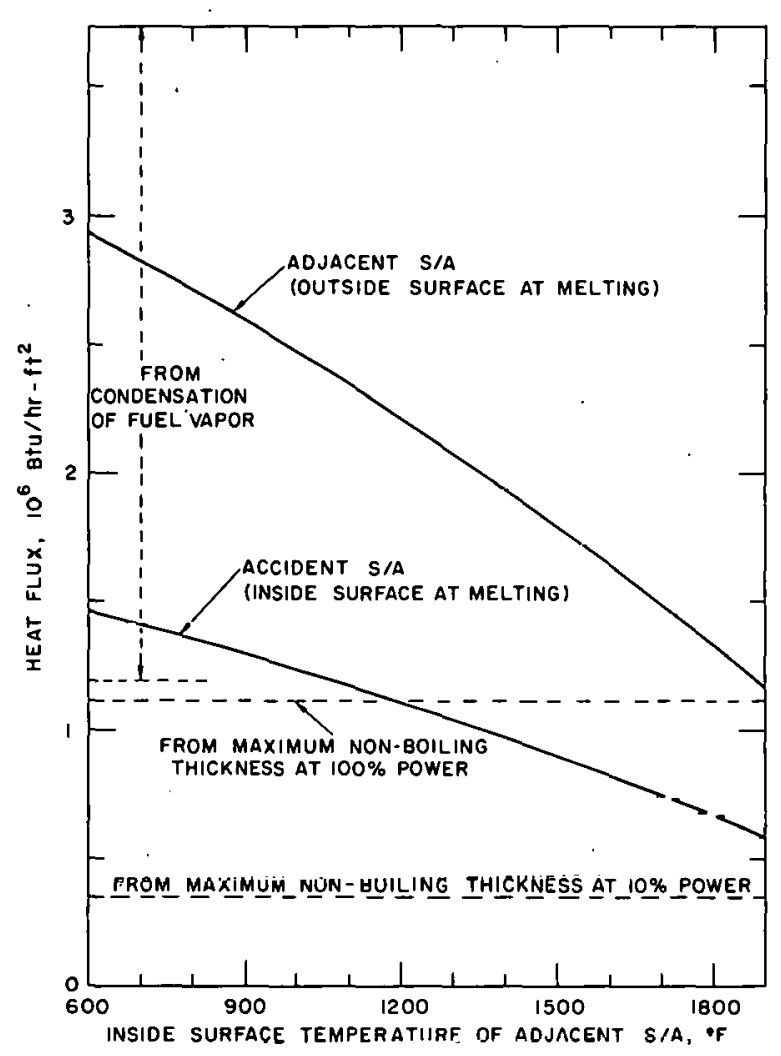

Fig. 5. Heat-removal Capability of Accident and Adjacent Subassembly Duct. in the previous studies a layer of molten fuel was assumed to be instantaneously brought into contact with the subassembly duct. For the steady-state full-power conditions, at least some melting of the accident subassembly duct would be expected to occur upon contact with molten fuel, but the duct may not completely melt through if the fuel is deposited in the lower part of the core, where the coolant temperature in the adjacent subassembly is lower. The much higher heat-removal capability of the adjacent subassembly duct would prevent its complete meltthrough, although some melting upon initial contact with molten fuel may ucur. Inder shit down conditions, the accident subassembly duce would not be expected to melt through if $1 t$ can survive the initial contact with molten fuel. The concept of a nonboiling fuel thickness implies the existence of a core of boiling liquid which condenses elsewhere, and the estimated heat fluxes due to fuel-vapor condensation 20 can be considerably higher than that due to the maximum

nonboiling, thickness. Although these high condensation heat fluxes would be reduced by an order of magnitude by the existence of noncondensible gases, substantial duct melting may occur in the region of fuel condensation.

In conclusion, it is difficult to prevent melting of the accident subassembly duct when it is suddenly contacted by molten fuel unless significant thermal resistances develop at the fuel-duct interface and sufficient convection in the interassembly gap sodium exists. Even for amounts of molten fuel as small as $1 / 2$ in. in diameter and 0.1 in. thick, complete meltthrough of the duct might occur unless boiling of the sodium in the interassembly gap can be prevented by sufficient convection mechanisms. Complete meltthrough of an accident subassembly duct is not expected to occur under certain less conservative assumptione, buch as a fuel layer less than the maximum nonboiling thickness or a more gradual deposition of fuel on the duct. The heat-removal capability of the duct wall is large enough to remove the heat generated by the fuel deposited on the inside surface if the initial effects of molten-fuel contact can be overcome and coolant temperatures in the adjacent subassembly can be maintained below about $1200^{\circ} \mathrm{F}$. Coolant temperatures in the adjacent subassembly have been investigated in detail by Marr. ${ }^{2}$ 


\section{Therma1 Stress Analysis of Subassembly Duct}

When the accident subassembly duct is subjected to a severe temperature gradient, it may fail due to thermal stresses even if melting of the duct does not occur. This case is applicable to situations in which relatively small quantities of molten fuel are deposited on the duct or when local blockages in the region of the duct wall might lead to local boiling or to release of small amounts of fuel debris which lodge against the duct wall.

There have been few analytical studies of thermal stresses in the subassembly duct. Coffield and Wattelet ${ }^{8}$ analyzed the adjacent subassembly duct using the FEATS finite-element computer code when the outside surface was at $2200^{\circ} \mathrm{F}$ and the inside surface at $1200^{\circ} \mathrm{F}$, which was considered to be conservative. It was found that the thermal stresses exceeded the yield strength; therefore cracking of the duct would occur if the rupture strain of $0.5 \%$ was assumed. The same conclusion would probably apply if the temperature gradient was from the inside surface to the outside surface.

Kennedy ${ }^{21}$ analyzed a very local hot spot (a square, 0.25 by 0.25 in.) on the subassembly duct using the SLADE finite-element computer code. Figure 6 shows the geometry considered and some of the results obtained. Assuming that the duct material had an extremely low ductility $(\sim 0.2 \%)$ and that failure occurs when the stresses exceed the yield strength, he found that local failure throughout the entire duct wall thickness would occur when the inside surface reached $1750^{\circ} \mathrm{F}$ (about the boiling temperature of sodium). The temperature gradient through the thickness of the duct wall was only $275^{\circ} \mathrm{F}$, but the temperature gradient in the transverse direction was $650^{\circ} \mathrm{F}$ on the inside surface and $375^{\circ} \mathrm{F}$ on the outside surface.

The above studies assumed either all six flats of the duct were subjected to a high temperature gradient or failure occurred when the yield stress was reached. Both assumptions appear to be overly conservative.

To extend the previous work on thermal stresses, a preliminary elastic-plastic model was developed to predict the behavior of the accident subassembly duct subjected to asymetric thermal loadings.

\section{a. Temperature Gradient}

The model consisted of a hexagonal subassembly duct, originally at constant temperature, which is subjected to a uniformly distributed high temperature on the inner surface of one flat and a linear temperature gradient through the thickness of this flat. The outer surface of this flat is maintained at the original interassembly sodium temperature along with the other five flats of the subassembly duct. The subdssembly duct was assumed to be very long, thus neglecting longitudinal variations and end effects. An elastic-perfectly plastic stress-strain relationship was assumed for the duct material.

The elastic thermal stress analysis is approximated by using a frame-structure analysis, 22 and therefore the thermally induced loading is shared by all the flats of the hexagonal duct. It is assumed 
$T(x)=[T(0)-1100] \exp \left[-(-x / 0.05)^{2}\right]+1100^{\circ} \mathrm{F}$

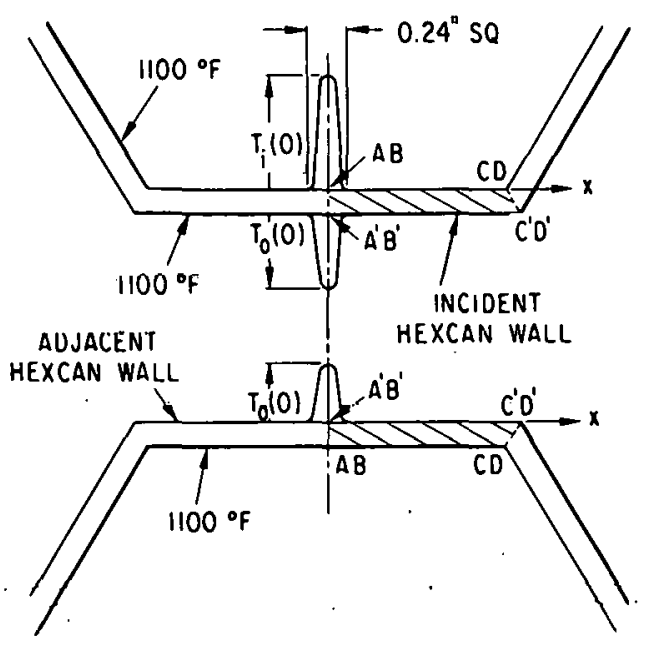

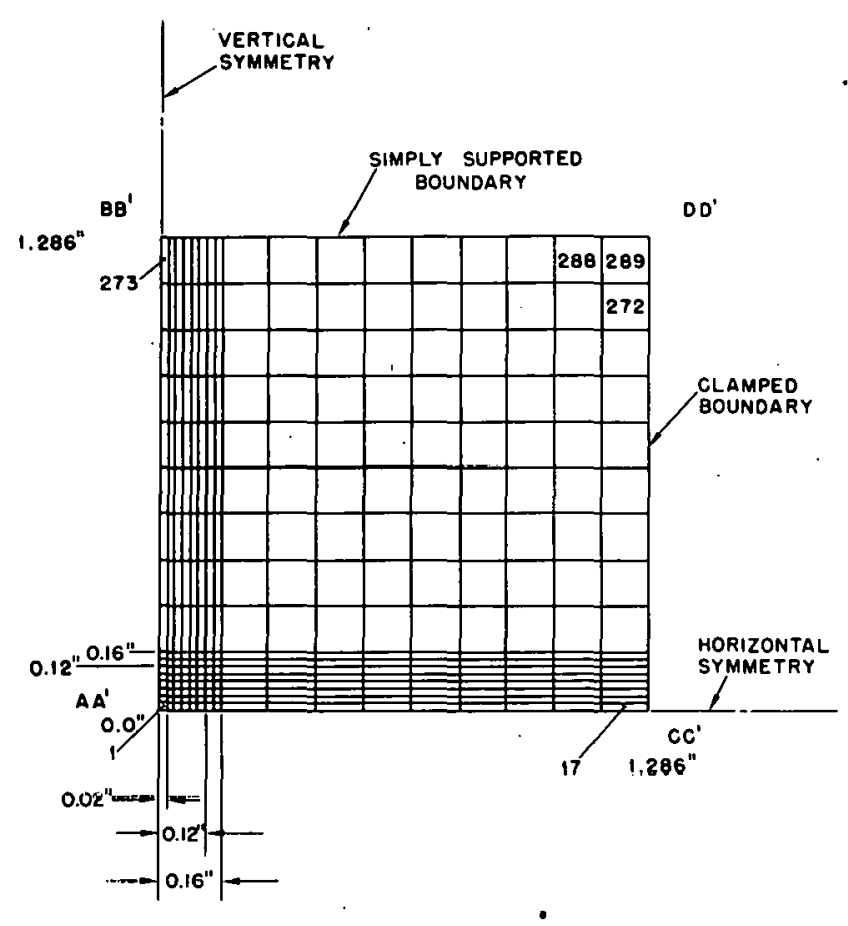

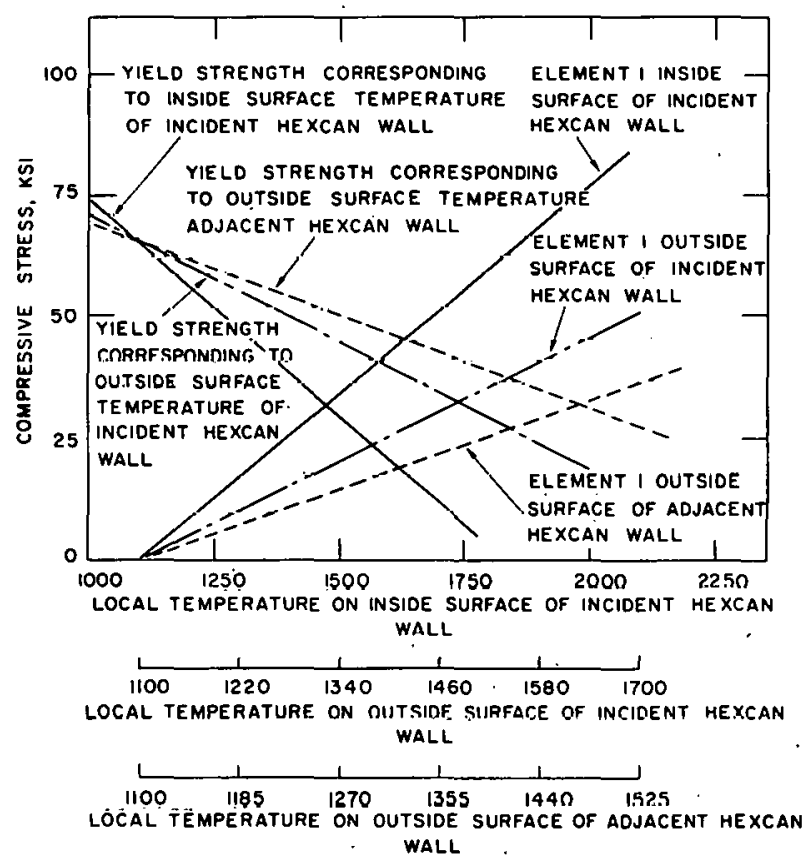

Fig. 6. Thermal Stress Analysis of Local Hotspot on Subassembly Duct. (From Ref. 21). 
that the membrane stress developed in the flat is negligible. The largest temperature gradient that the subassembly can withstand elastically is

$$
\Delta \mathrm{T}_{\mathrm{y}}=\frac{60}{19} \frac{\sigma_{\mathrm{y}}}{\alpha \mathrm{E}}
$$

where $\sigma_{y}$ is the yield stress of the material, $\alpha$ is the thermal-expansion coefficient, and $E$ is the modulus of elasticity. Using values of $\sigma_{y}, \alpha$, and $E$ from the ASME Boiler and Pressure Vessel Code ${ }^{23}$ (see Appendix C), the temperature gradient $\Delta \mathrm{T}$ across the duct wall can be determined for unirradiated stainless Types 304 and 316 for outer surface temperatures up to $800^{\circ} \mathrm{F}$ as shown in. Fig. 7. From these two curves, Type 316 appears to be slightly stronger than Type 304 in resisting thermal loadings.

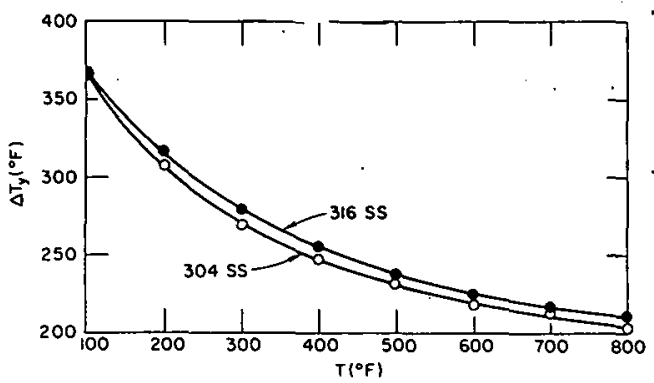

Fig. 7 .

Temperature-gradient Limits for Elastic Behavior of an Unirradiated Subassembly Duct WaZz. ANL Neg. No. 900-2269

For temperature gradients higher than those shown in Fig. 7, the duct wall will behave inelastically and a plastic analysis model is required. If the material has sufficient ductility, say greater than $0.4 \%$, it can be shown 24 that the inelastic bending moment is given by

$$
M=M_{F L}\left[1-\frac{1}{3}\left(\frac{\Delta T_{y}}{\Delta T}\right)^{2}\right]
$$

where $\mathrm{M}_{\mathrm{FT}}$ is the plastic flow moment denoting the theoretical ultimate plastic carrying capaclly of the duct wa11. Figure 8 shows how the inelastic bending moment varies with the temperature gradient. It is seen thal $\mathrm{M}$ approaches very close to $\mathrm{M}_{\mathrm{FL}}(\mathrm{M} \simeq 0.99 \mathrm{MFL})$ when $\Delta \mathrm{T}$ is about five times the value of $\Delta \mathrm{T}_{\mathrm{y}}$.

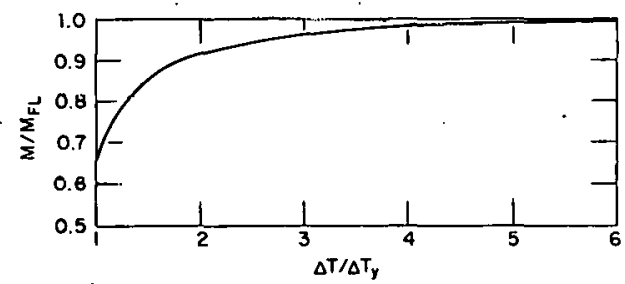

Fig. 8 .

Variation of Inelastic Bending Moment with Temperature Gradient.

ANL Neg. No. 900-2303

If $i t$ is assumed that the heated flat (i.e., the flat subjected to the temperature gradient) fails when $M \simeq 0.99 \mathrm{M}_{\mathrm{FL}}$, then Fig. 9 shows the temperature gradients which pruduce failure fnr original duct 


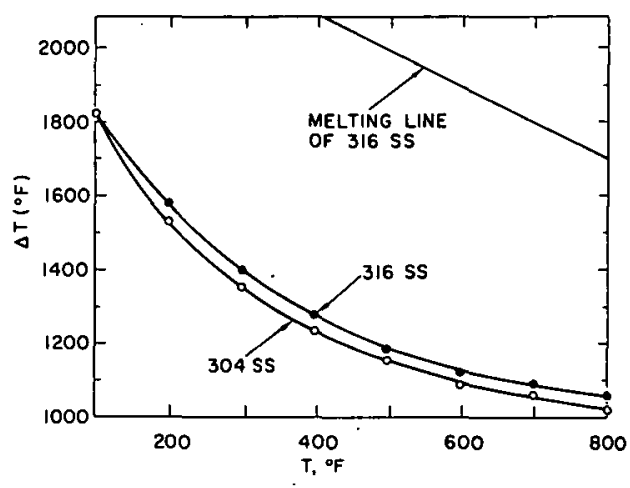

Fig. 9.

Temperature Gradient for Plastic Behavior of an Unirradiated Subassembly Duct Wall at $M \simeq 0.99 M_{F L}$. ANL Neg. No. 900-2294

temperatures from 100 to $800^{\circ} \mathrm{F}$ for unirradiated materials. In Fig. 9, the "melting line of 316 SS" corresponds to the inside surface being at the melting point and the outside surface at temperature $T$. Since the curves for the temperature gradient are significantly lower than the melting line, it appears likely that the duct might fail before $1, t$ reacheo the melting point.

For irradiated cold-worked stalnless steel Type 316, the material-property data generally show higher yield stress and reduced ductility compared to the unirradiated material25,26,27 (see Appendix C). By use of these data, it is possible to compare the maximum temperature gradients at high temperatures for both irradiated and unirradiated ducts in the elastic and inelastic range, as shown in Fig. 10. If the irradiated

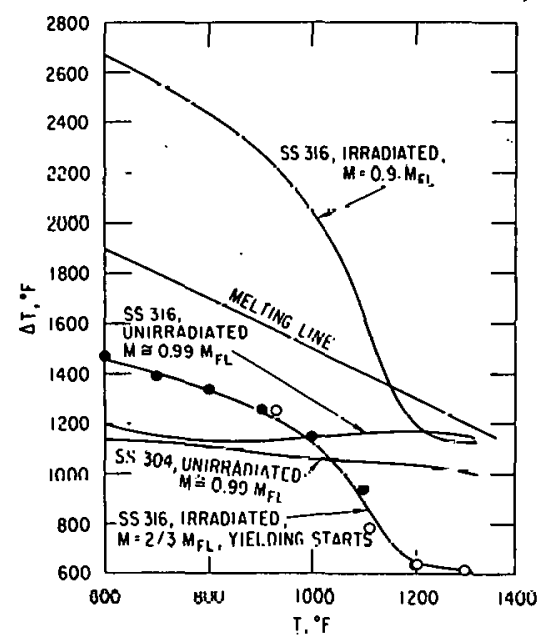

Eig. 10 .

Effect of Irradiation on Temperature Gradient for Elastic-Plastic Behavior of Subassembly Duct Walz. ANL Neg. No. 9001820 Rev. 1.

duct is assumed to have an extremely small ductility, which is thought to be a very conservative assumption, then it will fail when the thermally induced moment reaches the limiting elastic moment, i.e., $M=M_{y}=2 / 3 M_{F L}$. For this failure criterion, the irradiated duct can withstand relatively large temperature gradients only for outer surface temperatures below $1000^{\circ} \mathrm{F}$. However, failure will still occur before reaching the melting point of the duct.

If the irradiated duct is assumed to have some ductility, as the data indicate, then failure will not occur until significant plastic 
flow of the material is established, say $M=0.9 \mathrm{M}_{\mathrm{FL}_{L}}$. For this case, the irradiated duct has a much higher resistance against thermal loading than the fresh duct, and melting of the duct may occur before its failure due to plastic flow as shown in Fig. 10; however, its strength strongly depends on temperature, total amount of neutron fluence, ductility, and prestraining. More data on the properties of irradiated duct materials are definitely needed for an accurate assessment of the behavior of the irradiated duct.

\section{b. Combined Temperature Gradient and Internal Pressure}

If it is assumed that the subassembly duct is under a moderate internal pressure as well as a temperature gradient, the moment at the center of the flat increases as the temperature gradient across the flat is increased, and eventually it exceeds the elastic limit and reaches the elastic-plastic range. Although the moment is not uniformly distributed along the flat, failure can be assumed to occur when the center moment approaches very close to the plastic flow moment.

First, consider the case in which the linear temperature gradient is uniformly distributed along all six flats of the hexagonal duct. For the elastic range, the largest temperature gradient $\Delta \mathrm{T}_{\mathrm{y}}$ that the duct can withstand can be obtained from the equation

$$
\frac{\mathrm{pL}^{2}}{4 \mathrm{~h}^{2}}+\frac{\mathrm{E} \alpha \Delta \mathrm{T} y}{2}=\sigma_{\mathrm{y}} \text {. }
$$

Figure 11 shows $\Delta \mathrm{T}_{\mathrm{y}}$ for outer surface temperatures $\mathrm{T}$ up to $800^{\circ} \mathrm{F}$ for various values of pressure $p$ assuming $h=0.12$ in. and $L=2.641$ in. (thickness of FFTF subassembly duct wall and length of one flat, respectively). Unirradiated material properties of the duct were used in the calculations.

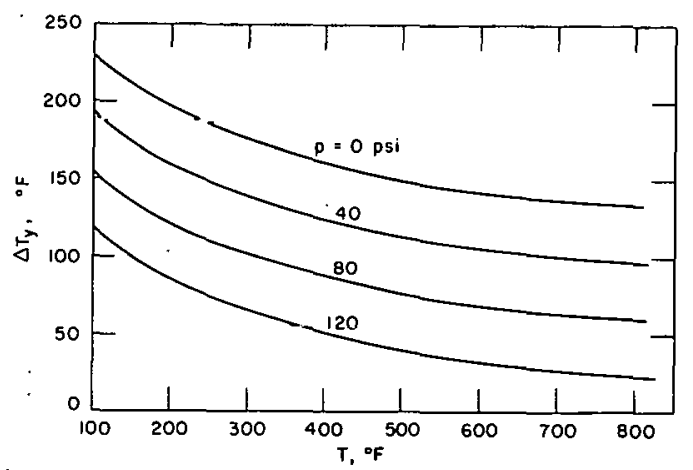

Fig. 11. Temperature-gradient Limits for Elastic Behavior of a Type 316 Stainless Steel Unirradiated Subassembly Duct Wall: Six Flats Heated.

In the elastic-plastic range, the inelastic bending moment $M$. can be obtained from the equation 


$$
M=M_{F L}\left[1-\frac{1}{3}\left(\frac{\sigma_{y}}{\frac{\mathrm{LL}^{2}}{4 \mathrm{~h}^{2}}+\frac{1}{2} E \alpha \Delta \mathrm{T}}\right)^{2}\right] ; \Delta \mathrm{T} \geq \Delta \mathrm{T}_{\mathrm{y}} \cdot
$$

If duct failure occurs when $\mathrm{M} \simeq 0.99 \mathrm{M}_{\mathrm{FL}}$, Fig. 12 shows the maximum temperature gradient $\Delta \mathrm{T}$ for various internal pressure. $\mathrm{p}$ and for outer sur-

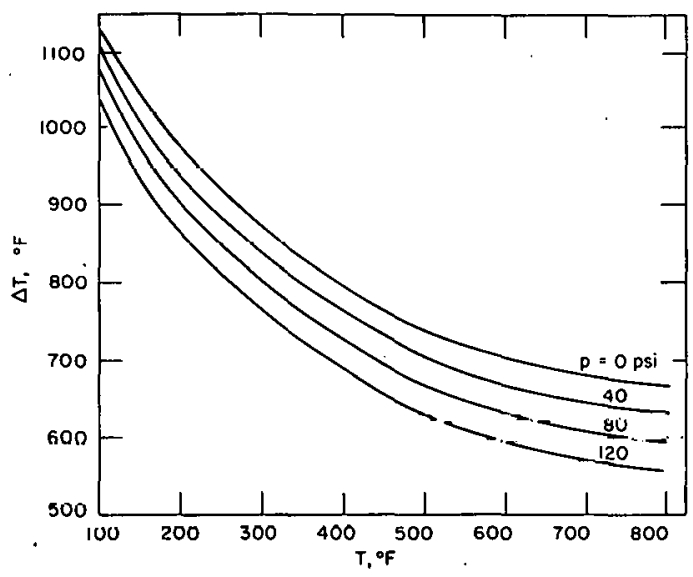

Fig. 12.

Temperature Gradient for Plastic Behavior of a Type 316 Stainless Steel Unirradiated Subassembly Duct Wall at $M \simeq 0.99 M_{F L}:$ Six Flats Heated.

face temperature up to $800^{\circ} \mathrm{F}$. As expected, the internal pressure decreaseo the allowable temperature gradient, and the duct wall would be expected to . fail far below its melting point.

A more realistic case to be considered is when the temperature gradient is uniformly distributed along only one flat of the duct in conjunction with a moderate internal pressure. The largest temperature gradient $\Delta \mathrm{T}_{\mathrm{y}}$ that the duct can withstand elastically can be obtained from the equation

$$
\frac{\mathrm{pL}^{2}}{4 \mathrm{~h}^{2}}+\frac{19}{60} \mathrm{E} \alpha \Delta \mathrm{T}_{\mathrm{y}}=\sigma_{\mathrm{y}}
$$

In the inelastic range, the bending moment $M$ is approximated by the equation

$$
M=M_{F L}\left[1-\frac{1}{3}\left(\frac{\sigma_{y}}{\frac{p^{2}}{4 h^{2}}+\frac{19}{60} E \alpha \Delta T}\right)^{2}\right] ; \Delta T \geq \Delta T_{y}
$$

The corresponding temperature gradients in the elastic and inelastic range are shown in F1gs. 13 and 14 for various internal pressures using unirradiated material properties for the duct. Since the internal pressure decreases the ability of the duct to withstand thermal loading, it appears that a ductile subassembly will not be able to withstand the combined action of moderate internal pressures and severe temperature gradients without failure. 

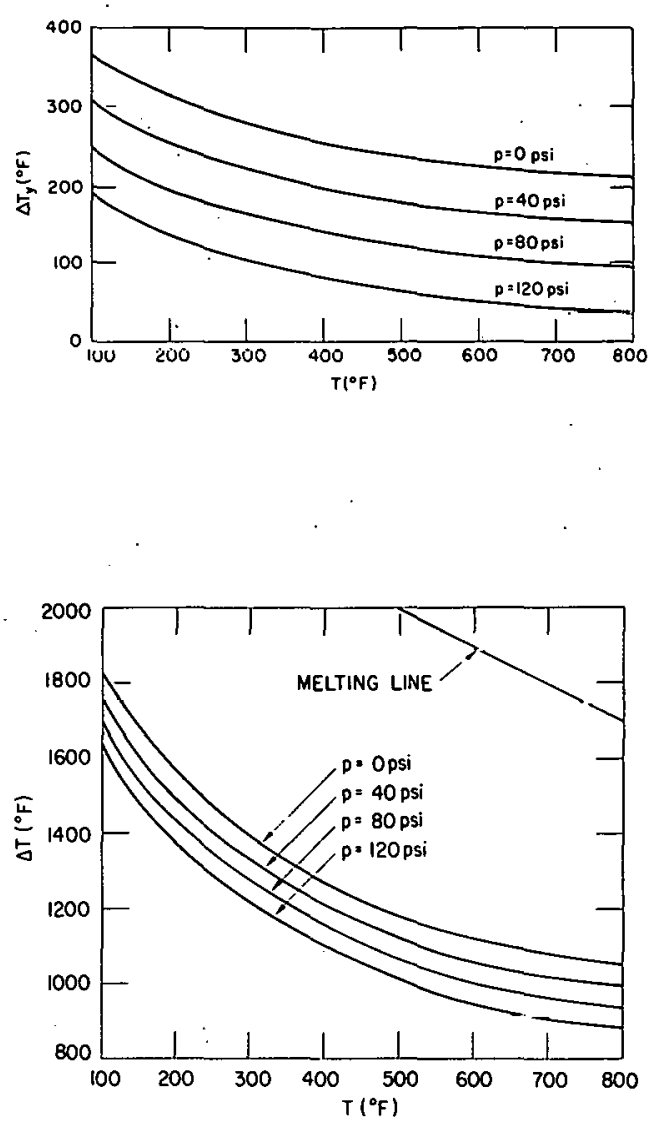

Fig. 13.

Temperature-gradient Limits for Elastic Behavior of a Type 316 Stainless Steel Unirradiated Subassembly Duct Wall: One Flat Heated. ANL Neg. No. 900-2304

Fig. 14 .

Temperature Gradient for Plastic Behavior of a Type 316 Stainless Steel Unirradiated Subassembly Duct WalZ at $M \simeq 0.99 M_{F L}$ : One Flat Heated. ANL Neg. No. 900-2298

For an irradiated duct at high temperature, Fig. 15 shows that the effect of moderate internal pressures is not significant enough to reduce the maximum temperature gradient completely below the melting line, although the crossover point occurs at lower temperatures. Therefore, in general, melting of the duct wall would be expected to occur before failure.

This preliminary assessment of the behavior of the subassembly duct wall under thermal and internal pressure loadings indicates that the irradiated duct may have significantly stronger resistance against thermal loading than the unirradiated duct. Although the present analysis provides insight into this complex problem, a more refined method (which would almost certainly involve computer implementation) would be required for additional detailed analyses.

\section{Coolant F1ow Diversion}

The integrity of a subassembly duct to maintain normal coolant flow can be violated either by a random duct failure or due to an environmental perturbation such as a large pressure pulse, a severe temperature gradient, or direct meltthrough by molten fuel. Failure of the duct could result in diversion of normal coolant flow out of the subassembly. This might cause a significant reduction of cooling capacity within the 


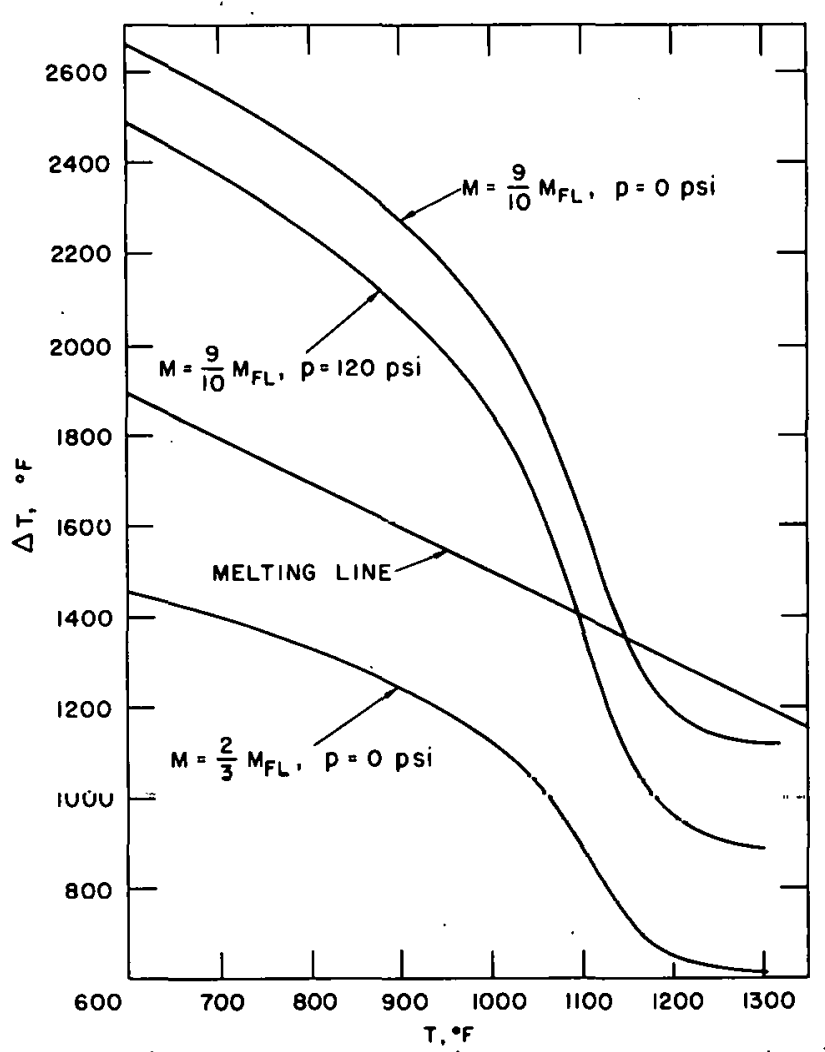

Fig. 15.

Temperature Gradient for ElasticPlastic Behavior of an Unirradiated Cold-worked Type 316 stainless Steel Subassembly Duct WaZZ.

subassembly and might result in local overheating near the rupture site or, for a large rupture, flow starvation in the entire subassembly. Since the problem of local coolant flow diversion out of a subassembly has not been treated previously, there were no available analytical models for handling this problem.

\section{Descrintinn of Mnde1.}

The COBRA-III ${ }^{28}$ computer code for thermal-hydraulic analysis of pin bundles was modified for this study by allowing for flow out of (or into) a coolant subchannel at any specified axial location(s). The case of flow out of the subchanned corresponds to coolant diversion out of the subassembly, whereas flow into the subchannel corresponds to injection of fluid in coolant-mixing experiments. The detalls of the modification of the equations for continuity, energy, and momentum are contained in Appendix B.

Various sizes of pin bundles, in some cases the typical FFTF 217-pin bundle, were analyzed. Results obtained for smaller bundles were used for extrapolation to the 217-pin bundle. This is necessary because of the excessive computer-core storage and run time required for analyzing the 217-pin bundle. All bundlcs were subjected to threc typce of rupturee at one of the corners of the hexagonal duct: a 1-in. rupture at midcore, an 18-in. rupture in the bottom half of the core region (which corresponds to the molten-fuel location in a severe overpower fuel pin), and a 36-in. rupture over the entire core region. Since the flow condition is not much different for an edge subchannel and a corner subchannel in the bundle, the 
general conclusion obtained for the rupture at a corner is expected to be applicable to ruptures anywhere around the subassembly duct. The fuel-pin geometry and operating conditions correspond to those of the typical FFTF maximum-power subassembly. ${ }^{7}$ Analyses of the 7- and 19-pin bundles were done for the initial-core conditions. Subsequent interest in the rated core required that different operating conditions be used in the analyses of the 61- and 217-pin bundles. These conditions are 1isted below along with the COBRA-III parameters used:

\begin{tabular}{|c|c|}
\hline Pin OD (in.). & 0.23 \\
\hline Pin-to-pin triangular pitch (in.) & 0.286 \\
\hline Heated length (in.) & 36 \\
\hline $\begin{array}{l}\text { Average fuel-pin linear power } \\
(\mathrm{kW} / \mathrm{ft})\end{array}$ & $\begin{array}{l}10.16(7-, 19-\text { pin }) \\
11.06(61-, 217-\text { pin })\end{array}$ \\
\hline $\begin{array}{l}\text { Axial power peaking factor } \\
\text { (chopped cosine) }\end{array}$ & 1.24 \\
\hline $\begin{array}{l}\text { Nominal inlet mass velocity } \\
\left(10^{6} \mathrm{lb}_{\mathrm{m}} / \mathrm{hr}-\mathrm{ft}^{2}\right)\end{array}$ & $\begin{array}{l}4.028(7-, 19-\text { pin }) \\
4.432(61-, 217-\text { pin })\end{array}$ \\
\hline Coolant inlet temperature $\left({ }^{\circ} \mathrm{F}\right)$ & $\begin{array}{l}600(7-, 19-\text { pin }) \\
792(61-, 217-\text { pin })\end{array}$ \\
\hline Numinal core $\Delta T\left({ }^{\circ} \mathrm{F}^{\prime}\right)$ & $\begin{aligned} 290 & (7-p i n) \\
-336 & (19-p i n) \\
366 & (61-p i n) \\
395 & (217-p i n)\end{aligned}$ \\
\hline $\begin{array}{l}\text { Crossflow resistance coefflclent, } \\
\mathrm{K}\end{array}$ & 0.5 \\
\hline $\begin{array}{l}\text { Geometry factor for conduction, } \\
\text { kg }\end{array}$ & 2.0 \\
\hline Turbulent-mixing parameters, $\beta$ & 0.025 \\
\hline Axial increment, $\Delta \mathrm{X}$ (in.) & $\begin{array}{c}0.1 \text { ( } 1-i n \text {. rupture) } \\
1.0 \text { (18- and } 36-i n . \\
\text { rupture) }\end{array}$ \\
\hline
\end{tabular}

The boundary conditions assumed in COBRA-III are a constant pressure at the top of the fuel bundle and the inlet flow distribution at the bottom. Although pressure boundary conditions both at the top and bottom of the fuel bundle would be more appropriate mathematically, the assumed boundary conditions are adequate, since the differences are expected to be small under normal conditions. For a local disturbance within the fuel bundle, such as a blockage or flow leakage due to duct rupture, the boundary conditions in COBRA-III would still be satisfactory as long as the disturbance is far enough away from the ends of the bundle. This is true for the 1-in. rupture at midcore, where the flow disturbance is limited to a few inches above and below the rupture. There are some errors in the 18and 36-in. rupture cases because the analysis begins at the bottom of the core region, where the rupture starts, instead of at the bottom of the fuel bundle, approximately $7 \mathrm{ln}$. below the bottom of the core region. However, 
the assumption of constant mass velocity at the bottom of the core region is conservative because there would have been more flow at the beginning of the rupture point if the flow diversion from the bottom of the fuel bundle had been taken into account; consequently, the coolant temperatures along the rupture would be expected to be lower than those calculated. The detailed wïre-wrap model in COBRA-III was not utilized for calculations; instead an equivalent turbulent-mixing parameter $\beta$ was used. A few check runs for both the 7- and 19-pin bundles showed that there was no significant difference in the predicted coolant temperature and flow distributions with or without the wire-wrap model.

The total mass flow to each bundle analyzed was assumed to remain constant with and without leakage flow due to subassembly duct rupture. In reality, the rupture might reduce the overall flow resistance of the subassembly and hence, might result in an increase in the inlet flow. In order to know how much flow would be expected to leak out of the subassembly from a duct rupture, the complicated flow paths in the region between the subassemblies must be determined. Consequently, the leakage flow was created as a parameter in this study inctead of assuming various rupture widths. The maximum amount of leakage flow which could be analyzed was limited by the inability of present computer codes to handle zero or reverse flow.

\section{Analysis and Results}

Figures 16 through 19 show the subchannel layouts for 7-, 19-, 61-, and 217-pin bundles, respectively. The symetry of the problem permits analysis of only one-half of each pin bundle. Analyses of the 7and 19-pin bundles were made for a full bundle to assess the effect of the wire-wrap model in COBRA-III. In this latter case, the leakage flow was assumed to come equally from the two subchannels surrounding the ruptured corner, e.g., subchannels 11 and 12 in the 7-pin bundle. Also notice that the subchannel divisions of the 61- and 217-pin bundles are coarser than those of the 7- and 19-pin bundles. This is necessary for the consideration of the requirement of computer-core storage and run time.

\section{a. 1-in. Rupture at Midcore}

For the 1-in. rupture at midcore, the axial flow varia tion in the subchannel adjacent to the rupture (i.e.., subchanne1 12 in the 7-pin bundle, 26 in the 19-pin bundle, and 31 in the 61-pin bundle) is shown in Fig. 20. For a leakage flowrate of $10.01 b_{m} / \mathrm{sec}-\mathrm{ft}$, the maximum decrease in subchannel flowrate is $42 \%$ in the 7 -pin bundle, $27 \%$ in the 19 -pin bundle, and $25.5 \%$ in the 61 -pin bundle. The Flow recovere somewhat. and settles to a new value after it passes the 1-in. rupture. The temperature variation around the rupture is shown in Fig. 21. The temperature difference between an interior subchannel and an exterior subchannel is grealer in a larger bundle. The hotter coolant in the interior subchannel is induced by the leakage to mix with the colder coolant in the exterlui subchannel adjacent to the rupture. Downstream of the rupture, however, the coolant temperature increases at a faster pace in the smaller-pin bundles where the decrease in flowrate is higher. At the outlet of the heated section, temperature increase is much larger in a small pin-bundle than in a larger pin-bundle, as shown in Fig. 22. 


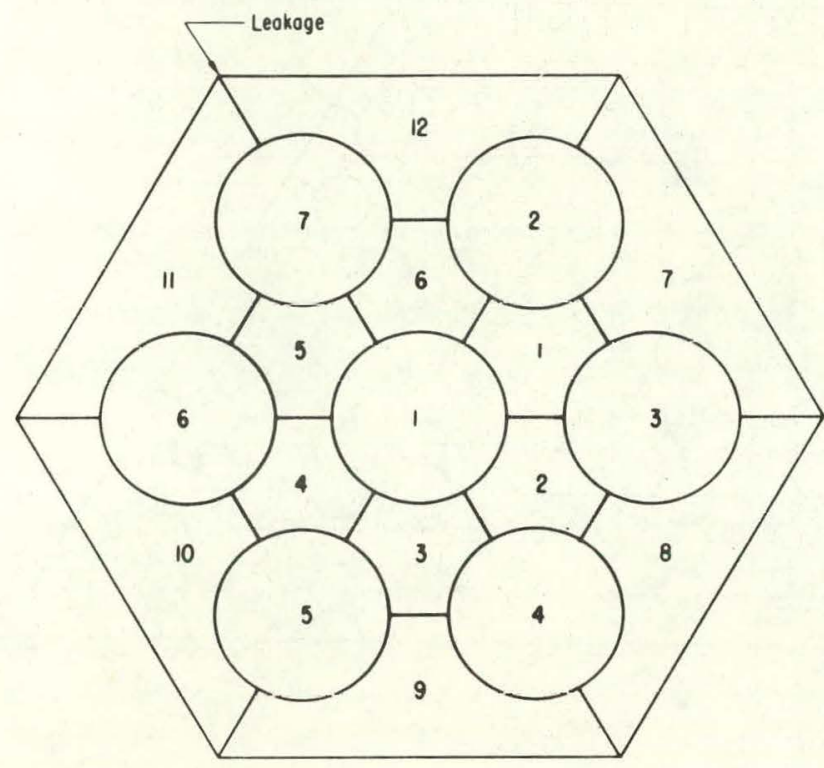

Fig. 16.

Subchannel Layout of a Seven-pin Bundle. ANL Neg. No. 900-3081.

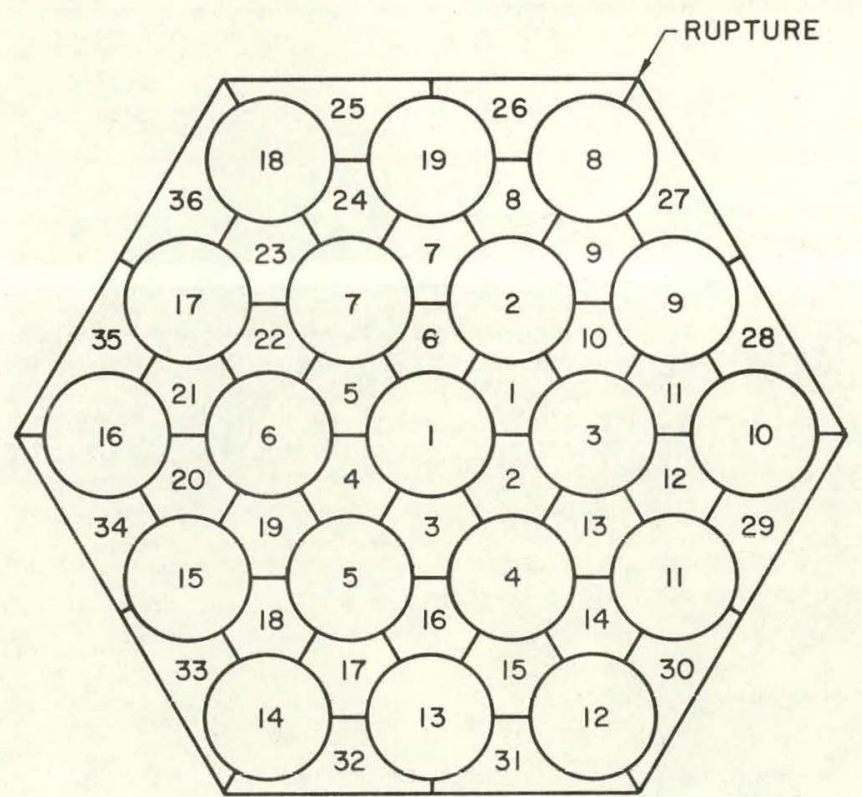

Fig. 17.

Subchannel Layout of a 19-pin Bundle.

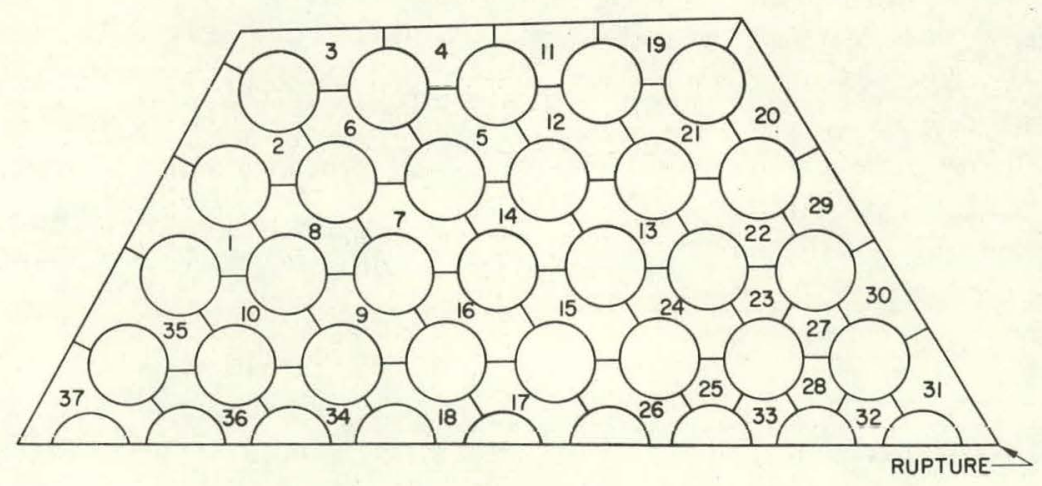

Fig. 18.

Subchannel Layout of a 61-pin Bundle.

ANL Neg. No. 900-4047. 


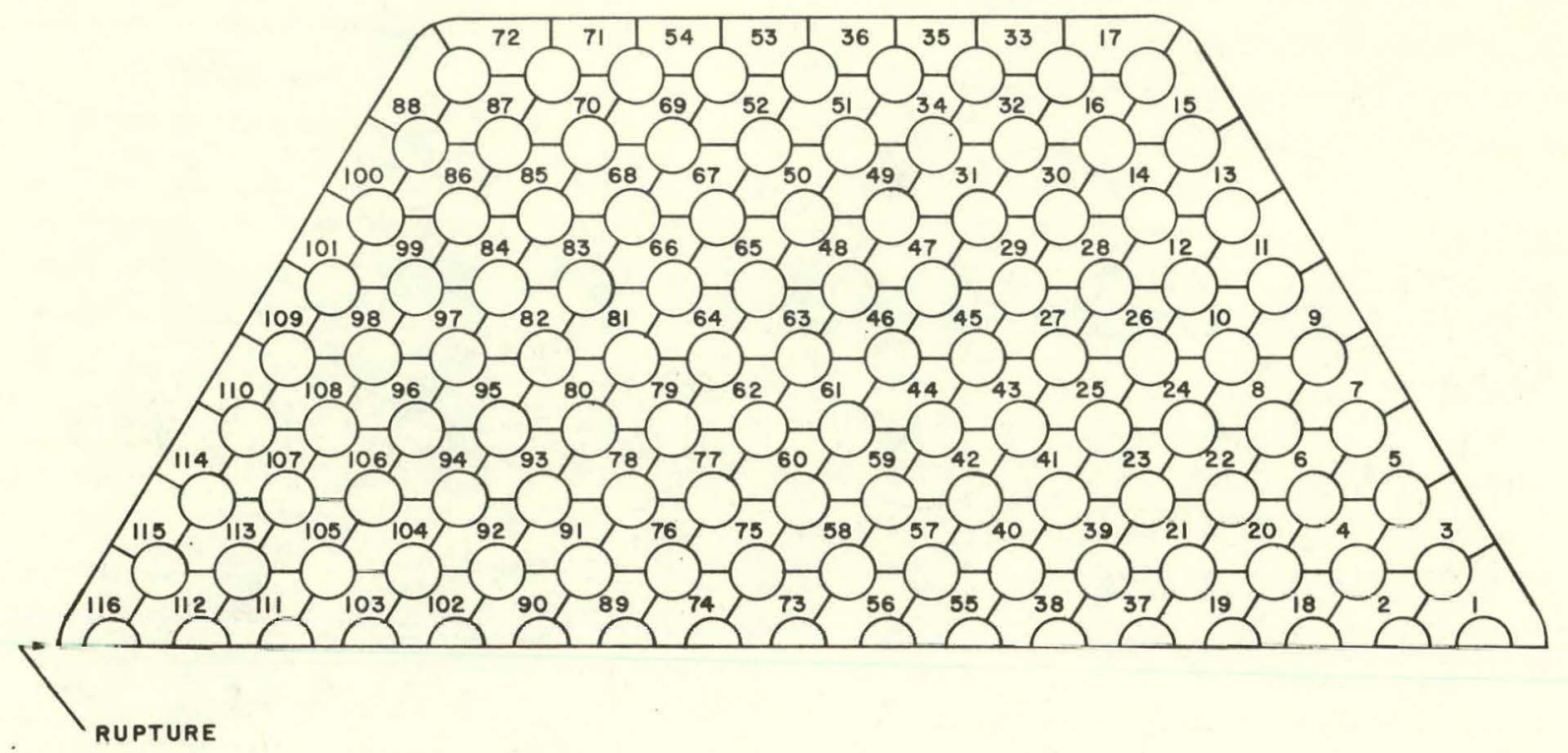

Fig. 19. Subchannel Layout of a 217-pin Bundle.
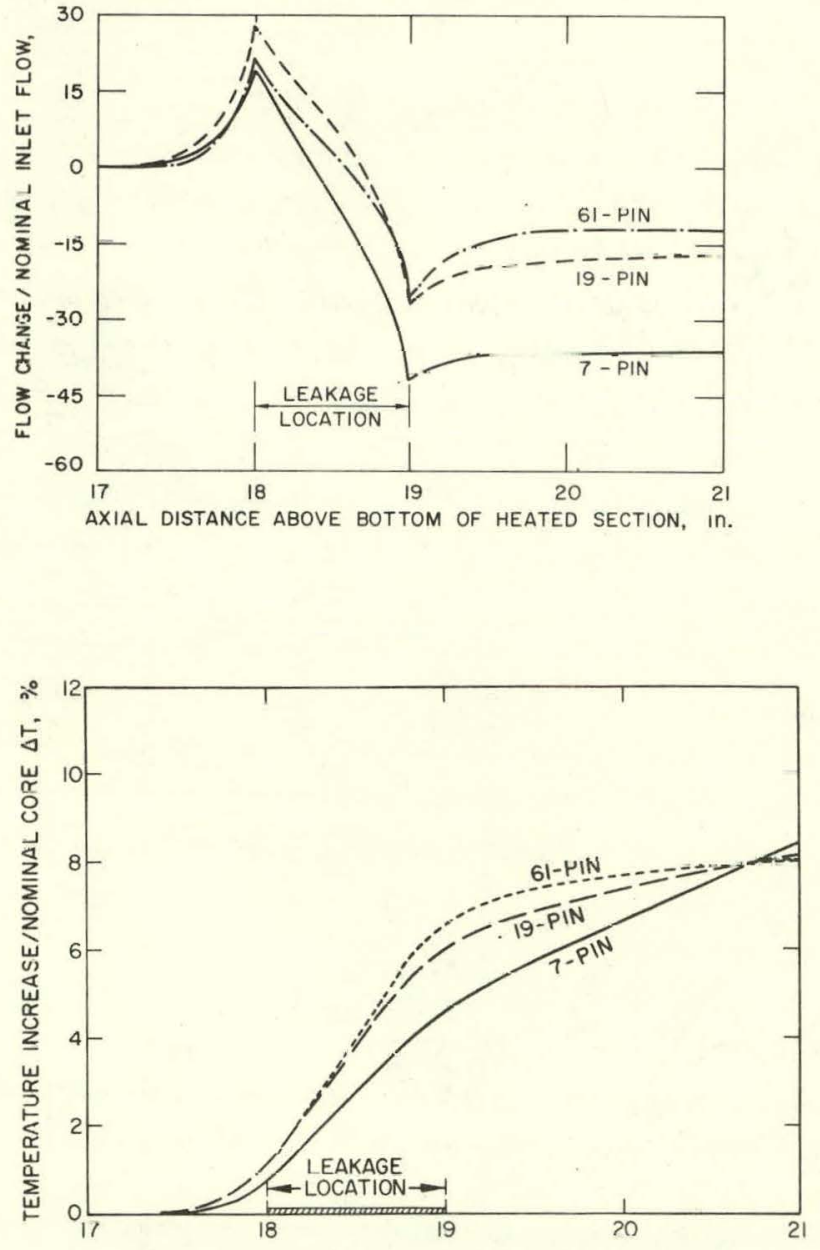

AXIAL DISTANCE ABOVE BOTTOM OF HEATED SECTION, in.
Fig. 20.

Local Flow Variation in the Subchannel Adjacent to a 1-in. Kupture at Midcore for a Leakage Flow Rate of $10.0 \mathrm{Zbm} / \mathrm{sec}-\mathrm{ft}$ in Various Pin. Bundles.

Fig. 21.

Local Temperature Variation in the Subchanne l Adjacent to a 1-in. Rupture at Midcore for a Leakage Flow Rate of $10.0 \mathrm{Zbm} / \mathrm{sec}-f$ t in Various Pin Bundles. ANL Neg. No. 900-4051. 


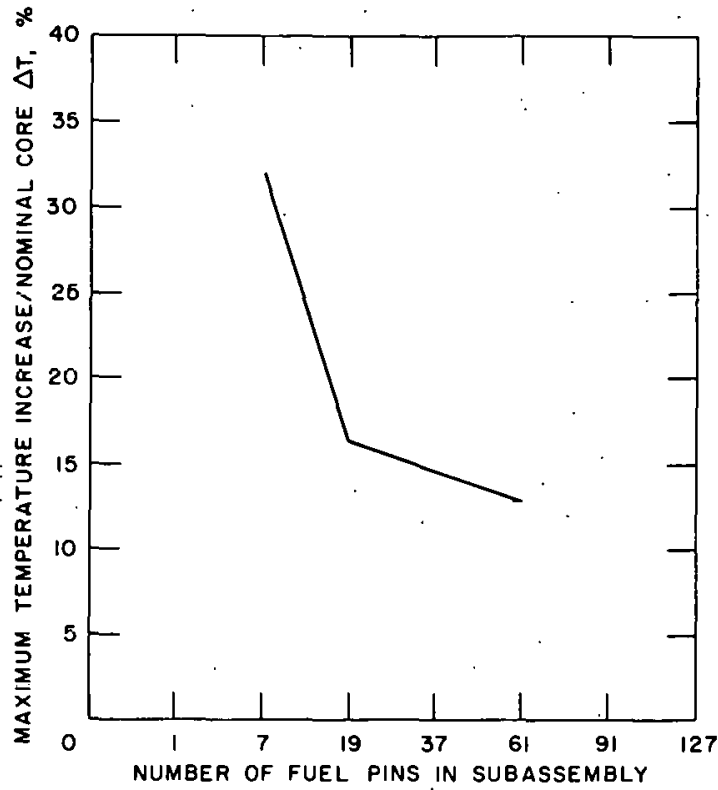

Fig. 22 .

Variation of Maximum Temperature Increase with Bundle Size for a Leakage Flow Rate of $10.0 \mathrm{Zb} \mathrm{rr} / \mathrm{soc}-\mathrm{St}$ along 1-in. Length at Midcore.

The effect of leakage flowrate on the flow and temperature distributions in the 7-pin bundle was also investigated. The leakage flowrate out of the 1-in. rupture was assumed to be $2.0,6.0$, and $10.01 \mathrm{bm} /$ sec-ft corresponding to 30,89 , and $148 \%$ of the normal subchannel flow. It is more meaningful to discuss the leakage flow in terms of subchannel

(Subchanne1 12) flowrates instead of total subassembly flowrates for such a localized situation. For the leakage flowrate of $2.01 \mathrm{~b}_{\mathrm{m}} / \mathrm{sec}-\mathrm{ft}$, the subchannel flow drops to $92 \%$ of its normal value at the end of the 1-in. rupture and then recovers to $93 \%$ after 2 in., as shown in Fig. 23. For a

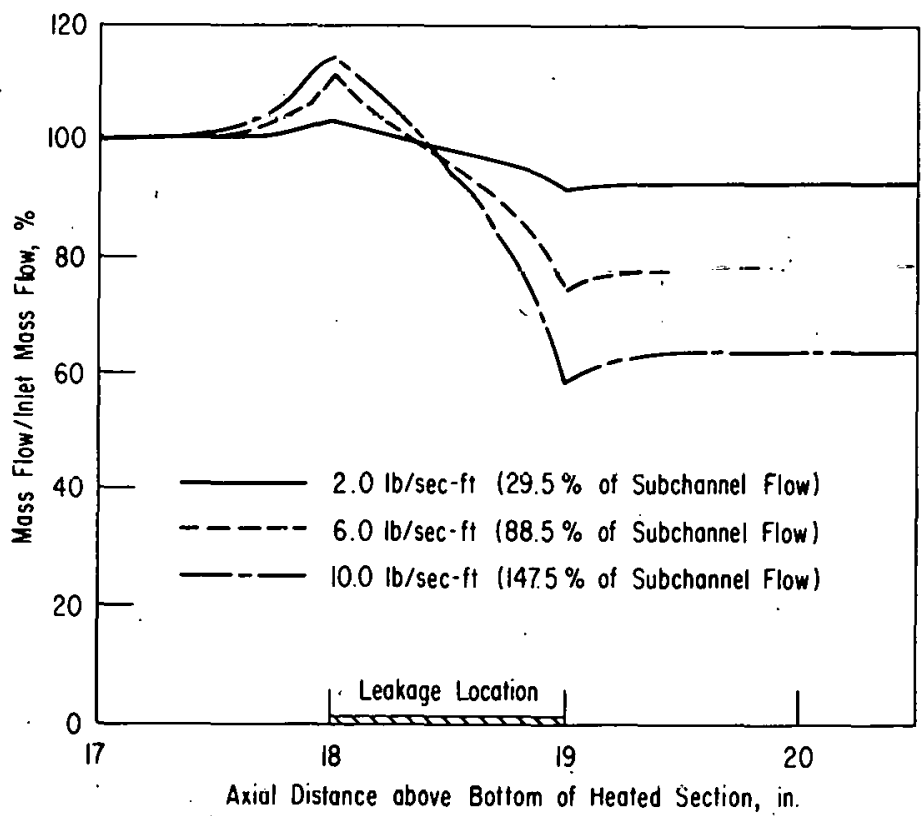

Fig. 23.

Local Flow Distribution in Subchannel 12 for Various Leakage Flow Rates alorig 1-in. Length at Midcore in the Seven=pin Bupulze.

leakage flowrate of $10.01 \mathrm{bm} / \mathrm{sec}-\mathrm{ft}$, the subchannel flow drops to $58 \%$ of ito normal value before recovering $L U 64 \%$ at $2 \mathrm{ln}$. beyond the end of the rupture. The local temperature increase in subchannel 12 due to these 
leakage flows is shown in Fig. 24. The temperature increase at 2 in. beyond the end of the rupture is less than $30^{\circ} \mathrm{F}$ for the case of $148 \%$ subchannel flow leakage.

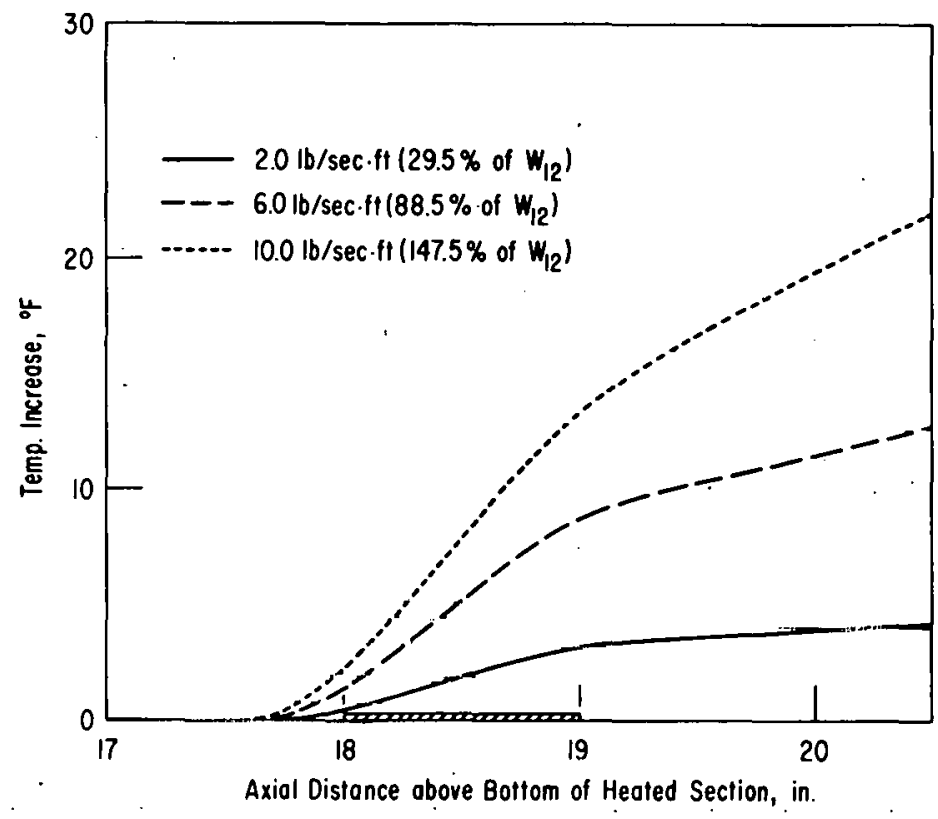

Fig. 24. Local Temperature Increases in Subchannel 12 for Various Leakage Flow Rates along 1-in. Length in the Seven-pin Bundle.

\section{b. 18-in. Rupture in Lower Half of Core}

For a leakage flowrate of $1.2 \mathrm{lb} / \mathrm{sec}-\mathrm{ft}$ over the lower half of the core region, where it is postulated that the hypothetical MFCI occurs, the maximum decrease in subchannel mass flowrate as a function of bundle size is shown in Fig. 25. The maximum decrease in subchannel mass

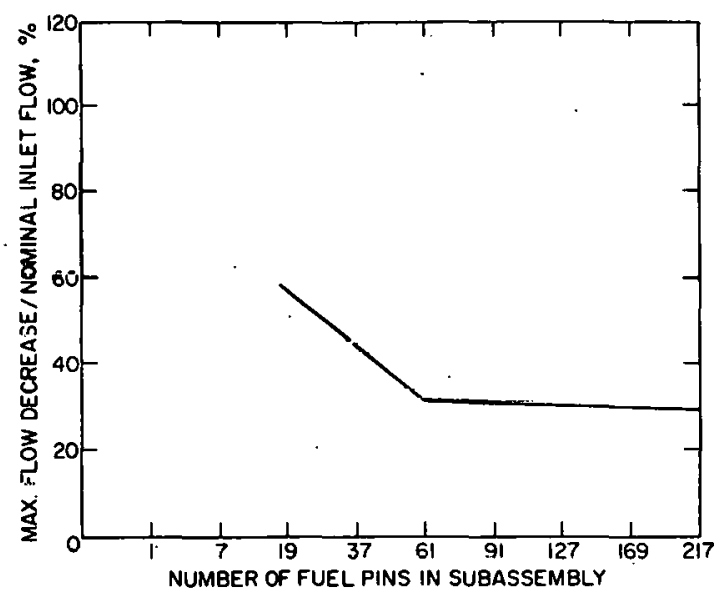

Fig. 25.

Variation of Maximum Decrease in Subchannel Flow Rate with Bundle Size for a Leakage Flow Rate of $1.2 \mathrm{lb} / \mathrm{sec}-\mathrm{s} t$ alurly Lower Ilalf of Heatod Longth. ANL Neg. No. 900-1053.

f1.owrate in the 19-pin bundle is about 60\%; in the 61-pin and.217-pin bundles it is close to $30 \%$. The maximum temperature increase as a function of bundle size for this case is shown in Fig. 26. Again, it can be seen that the perturbation decreases as the bundle size increases.

Figure 27 shows the effect of leakage flowrate on flow distribution in Subchannel 12 in the seven-pin bundle. The leakage flowrate 

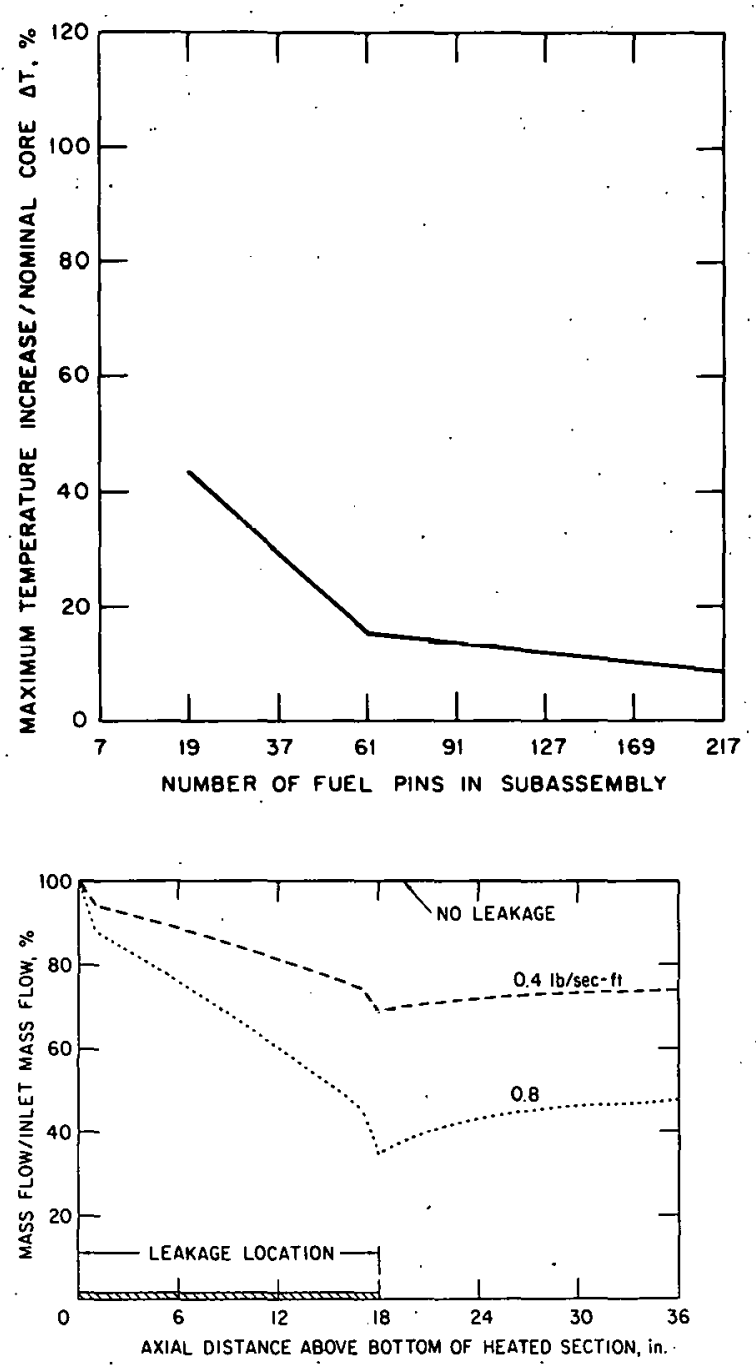

Fig. 26.

Variation of Maximum Temperature Increase with Bundle size for a Leakage Flow Rate of $1.2 \mathrm{Zb} / \mathrm{mec}$-ft along Lower Half of Heated Length. ANL Neg. No. 900-3435.
Fig. 27.

Flow Distribution in Subchannel 12 for Various Leakage Flow Rates along Lower Half of Heated Length in the Seven-pin Bundze. ANL Neg. No. 900-3073.

was varied parametrically from 0.4 to $0.81 \mathrm{bm} / \mathrm{sec}-\mathrm{ft}$, corresponding to 106 and $212 \%$ of the normal subchannel flow (26 and $52 \%$ of the total subassembly flow). The axial flow decrease along the length of the rupture was approximately linear, and the amount of decrease was proportional to the magnitude of the leakage flow. The flow recovery at the end of the rupture was much more gradual than for the 1-in. rupture. The axial temperature distribution in Subchannel 12 is shown in Fig. 28. The coolant temperature increase is

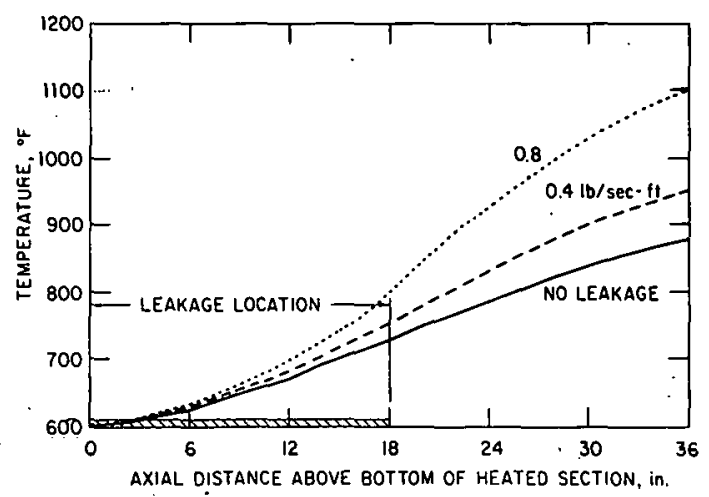

Fig. 28.

Temperature Vistribution in Subchannel 12 for Various Leakage Flow Rates along Lower Half of Heated Length in the Seven-pin Bundle. ANL Neg. No. 900-3075. 
more than proportional to the leakage flowrate increase since increasing flowrate from 0.4 to $0.8 \mathrm{1b} / \mathrm{sec}-\mathrm{ft}$ increases the coolant outlet temperature from 70 to $220^{\circ} \mathrm{F}$ above the normal coolant outlet temperature.

Figures 29 and 30 show the across-corners flow and temperature distributions in the 217-pin bundle at midcore and at the core outlet.
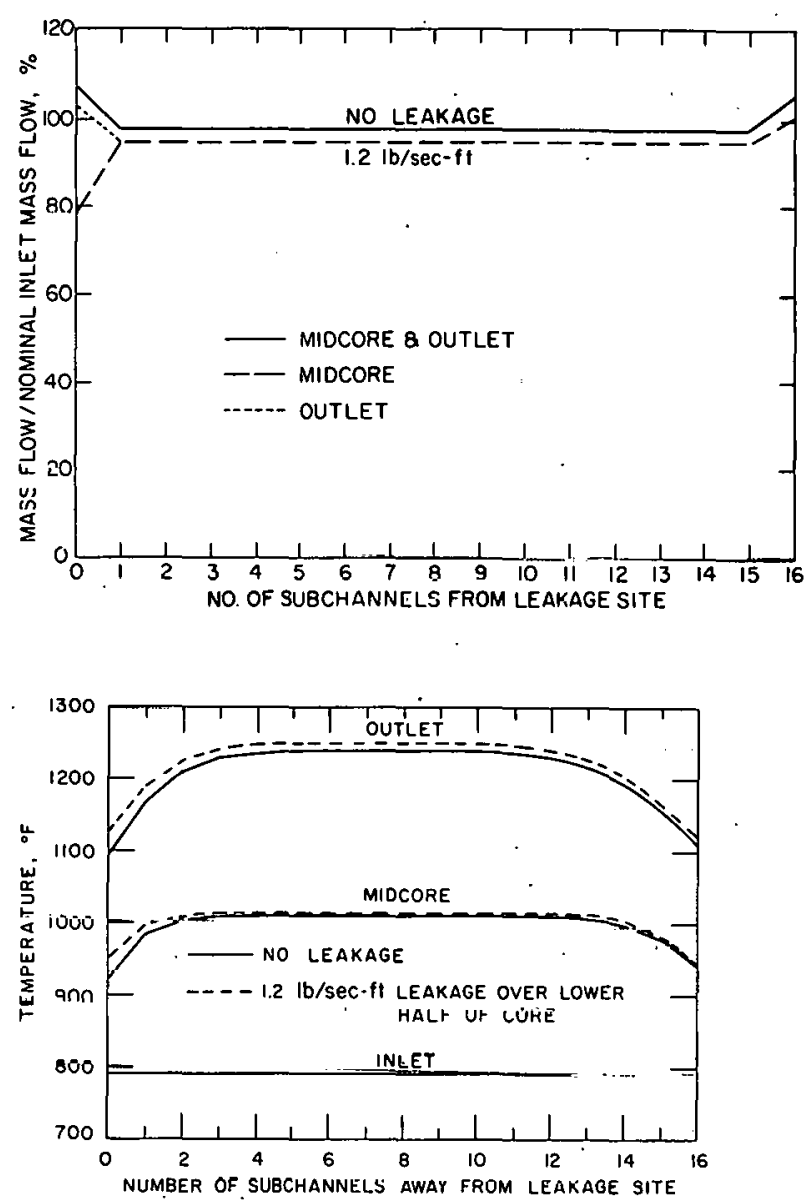

Fig. 29.

Effect of Leakage along Lower Half of Heated Length on Flow Distribution across the 217-pin Bundle. ANL Neg. No. 900-4045 Rev. 1.
Fig. 30 .

Effect of Leakage along Lower Half of Heatod Length on Temperature Distribution across the 217-pin Bundile. ANL Neg. No. 900-3444.

Aside from the subchannels adjacent to the rupture, the perturbatton in flow and temperature distribution in the ruwising suhehannclo at midcore is quite uniform. At the core outlet, $18 \mathrm{in}$. above the end of the rupture, the perturbation in flow is quite uniform across the whole bundle, while the perturbation in the coolant temperatures caused by the rupture decreases slightly away from rupture location, but the geveral shape of both distri. butions is malntained. Notice that the flow and temperature distributions are not exactly symmetric about the center of the pin-bundle because of the difference in dividing up the subchannels.

\section{c. 36-in. Rupture along Entire Core Length}

For a rupture along the entire $36-i n$. core length, the leakage flowrate was varied parametrically from 0.2 to $0.61 \mathrm{~b}_{\mathrm{m}} / \mathrm{sec}-\mathrm{ft}$. This corresponds to 106 to $318 \%$ of the normal subchannel flow or 26 to $78 \%$ of the total flow in the seven-pin bundle. Figure 31 shows the axial flow distr1bution in Subchannel 12 in the seven-pin bundle. As in the 18-in. rupture 


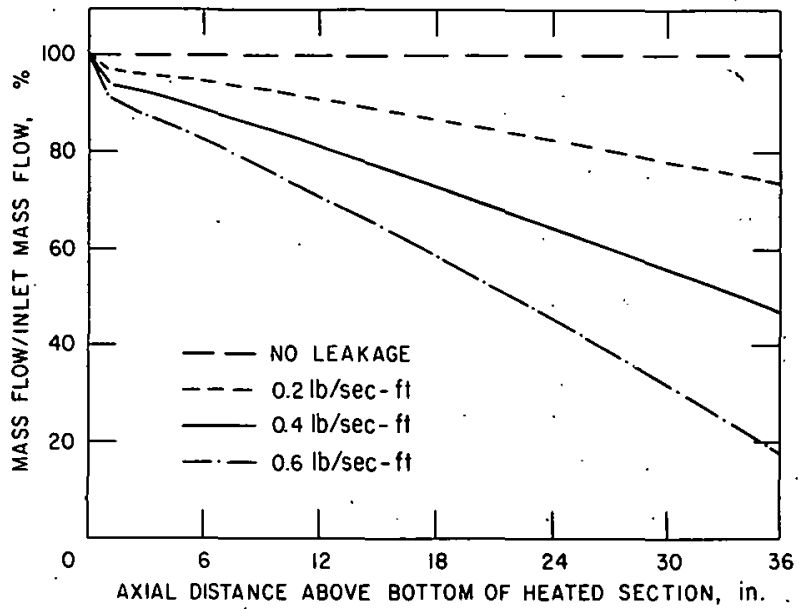

Fig. 31.

Flow Distribution in Subchannel 12 for Various Leakage Flows along the Entire Heated Length in the Sevenpin. Burille.

case, the axial flow decreases almost linearly along the rupture length and the amount of decrease is approximately proportional to the magnitude of the leakage flow. The coolant temperature increase, shown in Fig. 32, alos exhibits the same characteristics as the 18-in. rupture, in that the coolant outlet temperature increases faster than the variation in the leakage flow.

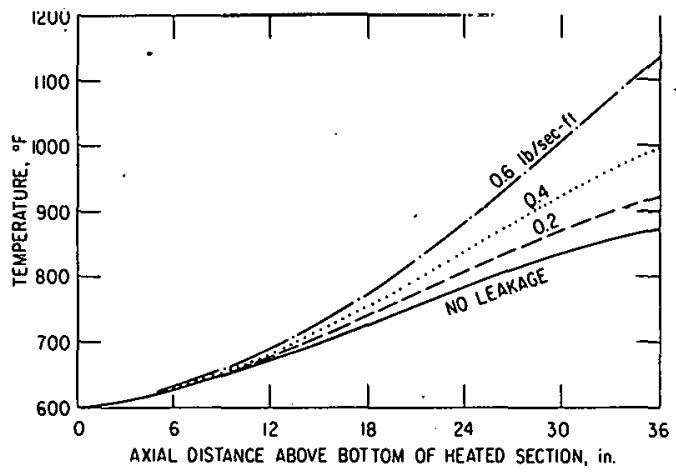

Fig. 32 .

Temperature Distribution in Subchannel 12 for Various Leakage Flows along the Entire Heated Length in the Seven-pin Bundle. ANL Neg. No. 900-3076 Rev. 1.

The axial coolant flow and temperature distributions in various pin-bundles for the 36-in. rupture with a leakage flowrate of $0.61 \mathrm{~b}_{\mathrm{m}} / \mathrm{sec}-\mathrm{ft}$, are shown in Figs. 33 and 34 . Figures 35 and 36 show the maximum decrease in subchannel mass flowrate and maximum coolant temperature increase, respectively, as a function of bundle size. As in the other types of ruptures; the perturbation to the subassembly coolant flow and temperature distributions for the same leakage flowrate decreases as the bundle size increases.

\section{Conclusions}

Results of the present study of coolant flow diversion out of the subassemblies indicate that for the same mass-leakage flowrate, the perturbation to the subassembly coolant flow and temperature distribution decreases as the bundle size increases. Therefore, the results indicate that there is no problem of local overheating for a leakage tlowrate up to $10.0 \mathrm{lb} / \mathrm{sec}-\mathrm{ft}$ for a 1 -in. rupture at midcore, up to $1.21 \mathrm{bm} / \mathrm{sec}-\mathrm{ft}$ for an 

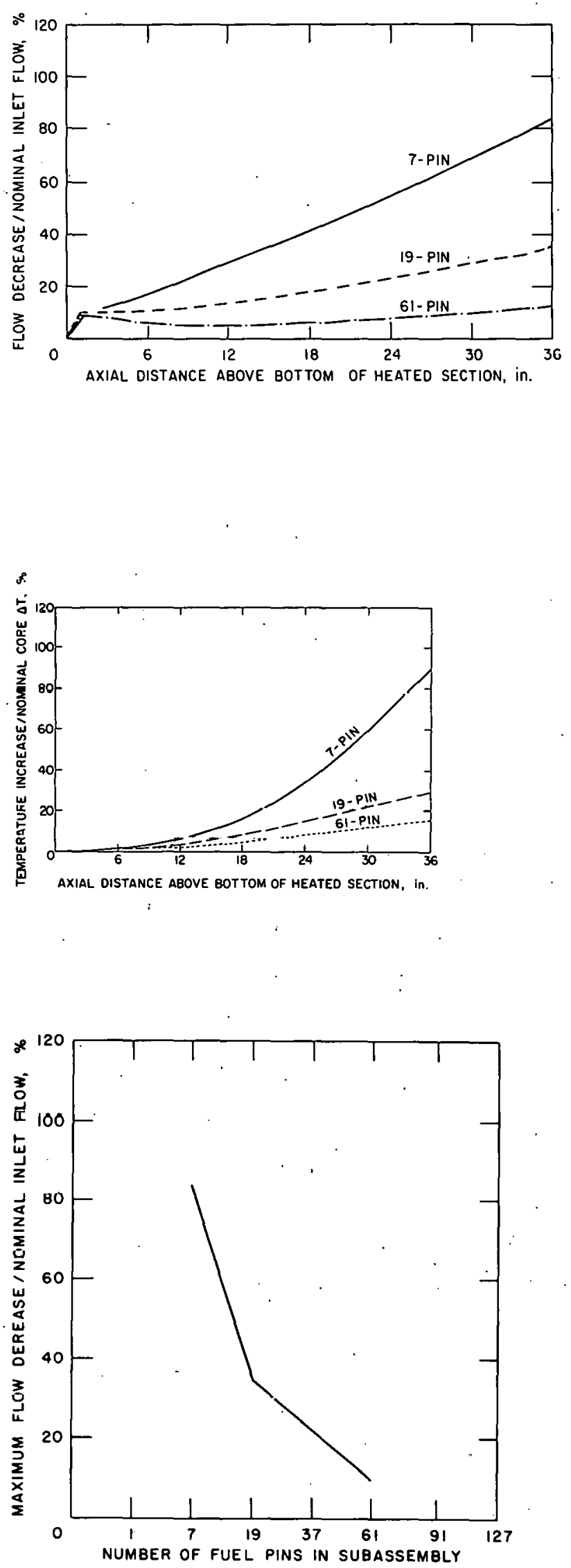

Fig. 33.

Axial Flow Variation in the Subchannel Adjacent to a 36-in. Rupture along the Entire Heated Length for a Leakage Flow Rate of $0.6 \mathrm{Zb} / \mathrm{sec}-\mathrm{ft}$ in Various Pin Bundles.
Fig. 34 . Axial Temperature Variation in the. Suhrhanne Z, Adjacent to a 36-in. Rupture along the Entire Heated Length for a Leakage Flow Rate of $0.62 b_{m} / \mathrm{sec}-f t$ in Various Pin Bundles.

ANL Neg. No. 900-4049.
Fig. 35.

Variation of Murimun Decrease in Subchannel Flow Rate with Bundle Size for a Leakage Flow Rate of $0.6 \mathrm{Zb} / \mathrm{sec}-f t$ along the Entire Healed Length. 


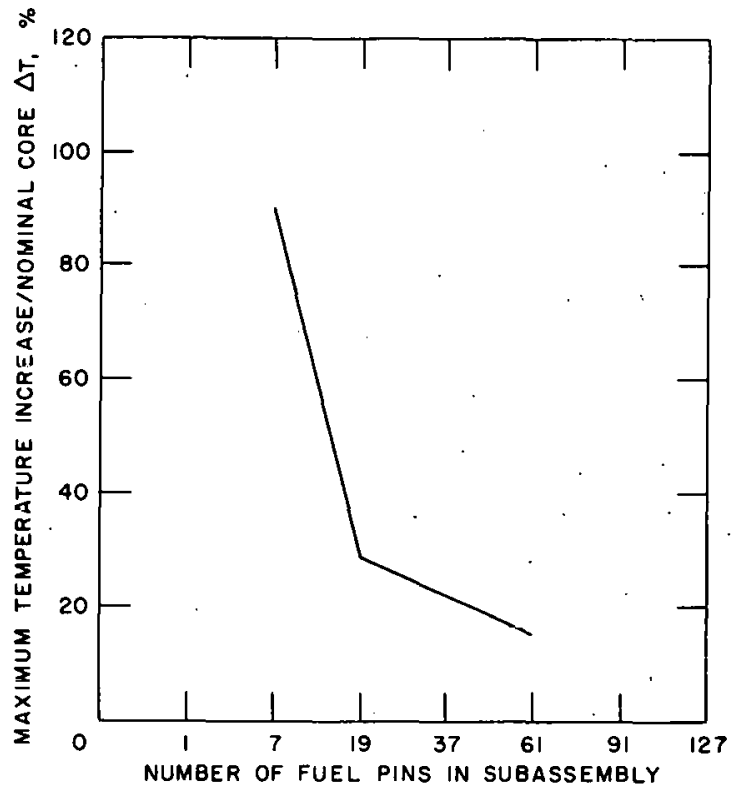

Fig. 36 .

Variation of Maximum Temperature Increase with Bundle size for a Leakage Flow Rate of $0.6 \quad 2 b_{m} /$ sec-ft along the Entire Heated Length.

18-in. rupture in the lower half of the core, and up to $0.61 \mathrm{~b}_{\mathrm{m}} / \mathrm{sec}-\mathrm{ft}$ for a 36-in. rupture along the entire core length.

Although these leakage flowrates correspond to a large fraction of the total flow for a small bundle, the fraction decreases as the bundle size increases. For example, a leakage flowrate of $0.61 \mathrm{bm} / \mathrm{sec}-\mathrm{ft}$ for a $36-$ in. rupture corresponds to $33 \%$ of the normal flow to a 19-pin bundle, but would correspond to only $3 \%$ of the normal flow of a 217-pin bundle. However, the total leakage flow corresponds to about three times the normal flow in the two coolant subchannels adjacent to the rupture for both 19and 217-pin bundles.

The results also indicate that a rupture in one of the corners of the hexagonal duct will not produce the hottest coolant temperatures in the region immediately adjacent to the rupture, but in the interior of the bundle, where the hottest coolant temperatures normally occur. This hottest region would be expected to be fairly broad, consisting of many coolant subchannels instead of a localized region.

\section{Assessment of Uncertainties}

The amount of leakage flow that can be analyzed is limited because of numerical instability problems arising from low or negative flows in the subchannels. To alleviate this problem, extensive modifications to the COBRA-III code would be required.

To ascertain the need for larger leakage flowrates, an analysis of expected leakage flowrates for various rupture widths should be carried out. This would require characterization of the torturous flow paths between the fuel subassemblies from the rupture location to the outlet plenum of the reactor. 
For larger flowrates, the resistance of flow in the transverse direction may become large enough compared to the flow resistance in the axial direction to limit effectively the amount of flow which can get to the rupture no matter how large it is. In addition to the numerical instability problem mentioned above, the COBRA-III code may not be valid for analyzing such large transverse flows because the model assumes that the crossflows are small in comparison with the axial flow. Therefore, if the need for much larger leakage flowrates is indicated by the analysis of the flow paths from the rupture to the outlet plenum, a new model to predict the transverse pressure drop within the fuel bundle may be required.

\section{SUMMARY AND CONCLUSIONS}

Based on a consideration of potential initiating faults and previous reactor operating experience, the effect of various mechanical and thermal loads on the integrity of the subassembly duct was assessed.

The severity of prcasure pulece from expected fission-gas releases or a local molten-fuel-coolant interaction (MFCI) are well within the capability of the subassembly duct to withstand. For a hypothetical local MFCI, improved dynamic elastic-plastic analytical models are expected to show that subassembly-duct failure is not expected.

Although subassembly-duct failure is not expected, various local ruptures in the subassembly were postulated in order to determine the perturbation in the coolant flow and temperature distribution resulting from coolant flow diversion out of the subassembly through the rupture. For the range of rupture flowrates.studied, it was concluded that there will be no local overheating due to a local rupture in the fuel subassembly.

Gross tued melting arlsing from a severe luss of flow to a single subassembly is not considered in chis report for the FFTF reaclui because the subassembly and reactur design preveuls the ocedrience of large suddull blockages. However, it is still possible for failure of the subassembly duct to occur if a local region of the wall is contacted by molten fuel greater than about 0.1 in. thick and about 1 in. in diameter. However, the heat-removal capability of the adjacent subassembly would prevent additional fuel or control-subassembly failure.

A model for stress analysis of the subassembly duct subjected to severe thermal gradient was developed. The results indicate that local fallure of an unirradiated subassembly duct would be expected before the duct starts to melc, but that an irradialed subassembly duct might start to melt before failure due to thermal stress. The much higher resistance of the irradiated subassembly duct to thermal loading is highly dependent on the material properties of irradiated stainless steel.

In conclusion, on the basis of current analytical and experimental results, it appears that the subassembly-duct integrity will not be violated for expected mechanical or thermal loads; for hypothetical accidents which result in severe mechanical and thermal loading, failure of the subassembly duct would probably occur. 


\section{APPENDIX A}

The Fuel-Melting Incident in the Enrico Fermi Reactor

\section{A. Description of the Incident ${ }^{5}$}

On October 5, 1966, the Fermi reactor was being subjected to a controlled, slow increase in power in order to investigate anomalous thermocouple readings which had been obtained at the outlets of several subassemblies during previous operation. At a power level of $31 \mathrm{MW}(t)$, it was noted (at about 3:05 PM) that the control rods appeared to be withdrawn further than normal for this power level. The reactor power increase was interrupted, and the thermocouples at the core outlet were checked. Abnormally high sodium temperatures at the outlet were indicated by the thermocouples over subassemblies $M-140$ and $M-098$, which were about 115 and $80^{\circ} \mathrm{F}$ higher than normal for those respectlve locatiuns.

Shortly thereafter, at 3:09 PM, radiation alarms were set off by detectors in both the containment building and the fission-productdetector building. A fission-product detector was also provided to monitor the primary argon gas for the decay products xenon and krypton, because the presence of these gases would indicate fuel failure. In fact, cover-gas samples were drawn from the reactor vessel and the primary pump tanks, but the detection of fission products involves a significant delay time. The reading for the cover-gas sample exposed between 2:58. and 3:01 PM was found to be off scale, and a gain check indicated no malfunctioning of the detector. Shortly after this gain check, the fission-product-detector building was automatically isolated from the reactor building by the radiation alarm. The reactor was manually scrammed at 3:20 PM.

Seven subassemblies were removed from the reactor after the incident and subjected to destructive examination. Only two subassemblies, M-127 and M-098 (see Fig. A.1 for their locations), had suffered extensive fuel melting, and holes were found in the adjacent faces of their ducts. Two other subassemblies, $M-122$ and $M-140$, had suffered some overheating, but their fuel pins and ducts were intact. Nothing was found in any subassembly that could have caused the fuel melting, but two of the six zirconium segments originally installed on a conical flow guide were found loose in the reactor inlet plenum. A series of hydraulic tests showed that one of the zirconium segments could have simultaneously produced nearly complete blockage ( $3 \%$ of normal flow) in subassemblies $M-127$ and $M-098$, and partial blockage in the two other subassemblies ( $10 \%$ in $M-122$ and $\sim 30 \%$ in $\mathrm{M}-140$ ). Abnormally high sodium temperatures at the outlet were not indicated by thermocouples over subassemblies $\mathrm{M}-127$ and $\mathrm{M}-122$.

\section{B. Thermal-hydraulic Analysis of the Inctdent ${ }^{6}$}

A thermal-hydraulic analysis showed that reduction of the subassembly flow to approximately $3 \%$ of the normal value would lead to sodium bolling and fuel melting. Based on this analysis and all of the available evidence, the following sequence of events was suggested. 

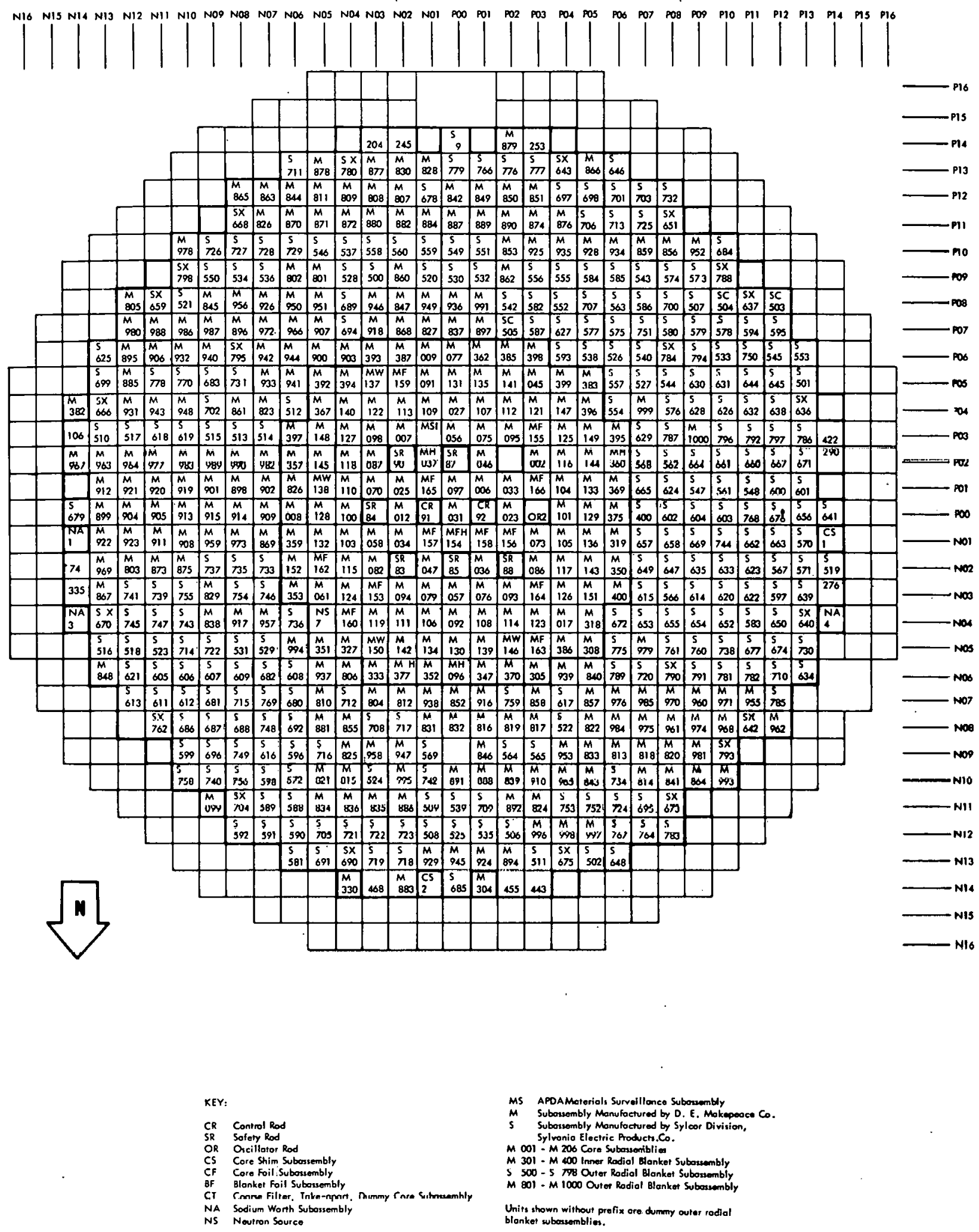

Fig. A.1. Fermi Reactor Loading on October 5; 1966. 
- A zirconium segment from the conical flow guide broke loose and produced nearly complete blockage of M-127 and M-098 (the accident subassemblies), and partial blockage of $\mathrm{M}-122$ and $\mathrm{M}-140$ (the adjacent subassemblies).

- As the reactor power level was increased, a sodium-vapor bubble filled the central region of the two accident subassemblies, where the coolant temperatures were above the boiling point of sodium.

- Fuel melting started at a reactor power level of 9 to $18 \mathrm{MW}(\mathrm{t})$, and clad failure occurred at temperatures of 2100 to $2600^{\circ} \mathrm{F}$.

- Within the region of the sodium-vapor bubble, the molten fuel flowed to the cooler sides and bottom of the bubble, and froze when coming into contact with the liquid sodium.

- Eventually, enough fuel slumped to form plugs in the accident subassemblies, which penetrated the duct walls.

- Sodium in the gap between the two accident subassemblies, which was nominally stagnant, entered the two subassemblies through the holes in the duct walls and provided appreciable convective cooling by two-phase flow through the vapor-bubble region. This convective cooling prevented additional fuel melting and failure propagation.

- The flow of liquid sodium induced in the interassembly gap provided cooling of the duct walls of the two accident subassemblies and prevented further penetration of the duct walls by molten fuel. 


\section{APPENDIX B}

\section{Modification of COBRA-III Computer Code for Leakage or Injection Flow}

COBRA-III 28 is a thermal-hydraulic computer code which calculates the transient coolant flow and temperature distribution in nuclear fuel bundles by considering turbulent and diversion crossflow mixing between the coolant subchannels.

To allow for leakage or injection flow into a subchannel, the following equations were modified:

\section{A. Continuity Equation}

For a control volume that consists of a segment of subchannel $i$ connected to an árbitrary subchannel $j$, the continuity equation in COBRAIII (Eq. A.2 in Ref. 28) is modified to become

$$
A_{i} \frac{\partial \rho_{i}}{\partial t}+\frac{\partial m_{i}}{\partial x}=-w_{i j}-w_{i, R},
$$

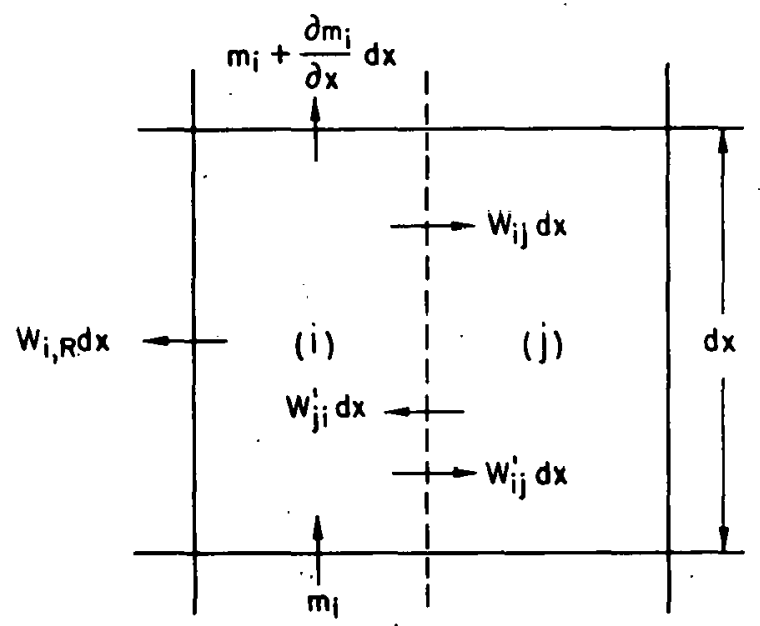

where $W_{i, R}$ is the leakage flow or injection flow, depending on whether its value is positive or negative, $i, e$, a positive $W_{i, R}$ denotes a leak.age f1nw out of subchannel (see accompnaying diagram). By considering a11 adjacent subchannels and taking $w_{i j}$ to be positive for flow from $i$ to $j, E q . B .1$ can be written as

$$
\begin{array}{r}
A_{i} \frac{\partial \rho_{i}}{\partial t}+\frac{\partial m_{i}}{\partial x}=-\sum_{j=1}^{N} w_{i j}-W_{i, R} ; \\
i=1,2, \ldots ., N .
\end{array}
$$




\section{B. Energy Equation}

written as

With leakage (or injection) flow, the energy equation can be

$$
\begin{gathered}
\frac{1}{u_{i}^{\prime \prime}} \frac{\partial h_{i}}{\partial t}+\frac{\partial h_{i}}{\partial x}=\frac{q_{i}^{\prime}}{m_{i}}-\left(T_{i}-T_{j}\right) \frac{c_{i j}}{m_{i}}-\left(h_{i}-h_{j}\right) \frac{W_{i j}^{\prime}}{m_{i}} \\
-h * \frac{W_{i j}}{m_{i}}-\frac{1}{m_{i}} \frac{\partial m_{i}}{\partial x} h_{i}-h_{R} \frac{W_{i, R}}{m_{i}},
\end{gathered}
$$

where $h_{R}$ is the enthalpy carried by the leakage (or injection) flow, $1 . e .$, for leakage flow out of the subassembly duct, it is the same as the local coolant enthalpy of subchannel $i . u_{i}^{\prime \prime}$ is the effective enthalpy transport velocity. For homogeneous two-phase flow or for single-phase flow, $u_{i}^{\prime \prime}=u_{i}$, the axial velocity in subchannel $i$.

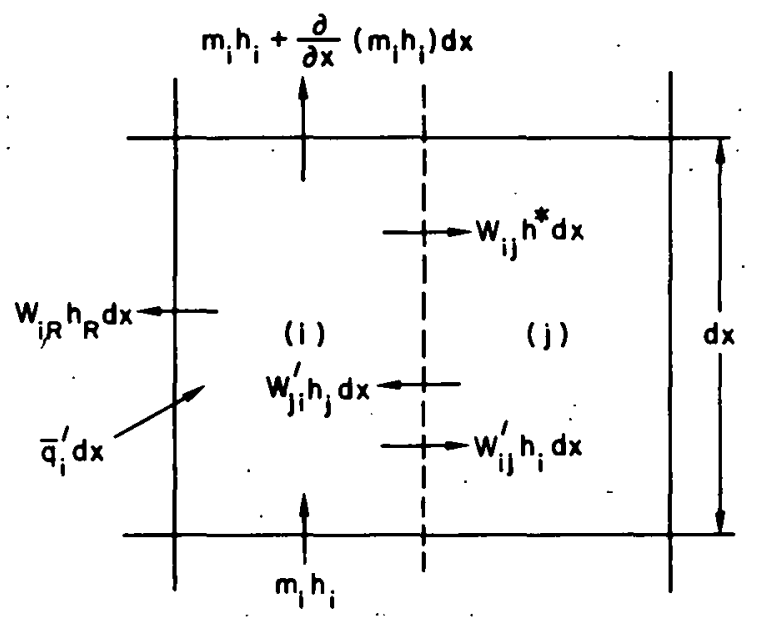

In the accompanying diagram, $\bar{q}_{1}^{\prime}$ represents the heat-transfer rate from the fuel surface, $q_{i}^{\prime}$, and the thermal-conduction term between subchannels $i$ and $j$. By using Eq. B.1 and neglecting $\partial \rho_{1} / \partial t$, and by considering all adjacent subchannels, Eq. B. 3 becomes

$$
\begin{gathered}
\frac{1}{u_{i}^{\prime \prime}} \frac{\partial h_{1}}{\partial t}+\frac{\partial h_{i}}{\partial x}=\frac{q_{i}^{\prime}}{m_{i}}-\sum_{j=1}^{N}\left(T_{1}-T_{j}\right) \frac{c_{i j}}{m_{i}}-\sum_{j=1}^{N}\left(h_{i}-h_{j}\right) \frac{W_{i j}^{\prime}}{m_{i}} \\
\quad+\sum_{j=1}^{N}\left(h_{i}-h^{*}\right) \frac{w_{i j}}{m_{i}}+\left(h_{i}-h_{R}\right) \frac{w_{i, R}}{m_{i}}
\end{gathered}
$$


which, for leakage flow where $h_{R}=h_{i}$, is identical to the energy equation used in COBRA-III (Eq. A. 8 in Ref. 28).

\section{Axial Momentum Equation}

The axial momentum equation used in COBRA-III (Eq. A.15 in Ref. 28) is modified to become

$$
\begin{aligned}
\frac{1}{A_{i}} \frac{\partial m_{i}}{\partial t}-2 u_{i} \frac{\partial \rho_{i}}{\partial t}+\frac{\partial p_{i}}{\partial x}=-\left(\frac{m_{i}}{A_{i}}\right)^{2}\left[\frac{v_{i} f_{i} \phi}{2 D_{i}}+A_{i} \frac{\partial}{\partial x}\left(\frac{v_{i}^{\prime}}{A_{i}}\right)\right] \\
\quad-g \rho_{i} \cos \theta-f_{T} \sum_{j=1}^{N}\left(u_{i}-u_{j}\right) \frac{W_{i j}^{\prime}}{A_{i}} \\
+\sum_{j=1}^{N}\left(2 u_{i}-u^{*}\right) \frac{W_{i j}}{A_{i}}+\left(2 u_{i}-u_{R}\right) \frac{W_{i, K}}{A_{i}}
\end{aligned}
$$

(see accompanying diagram).

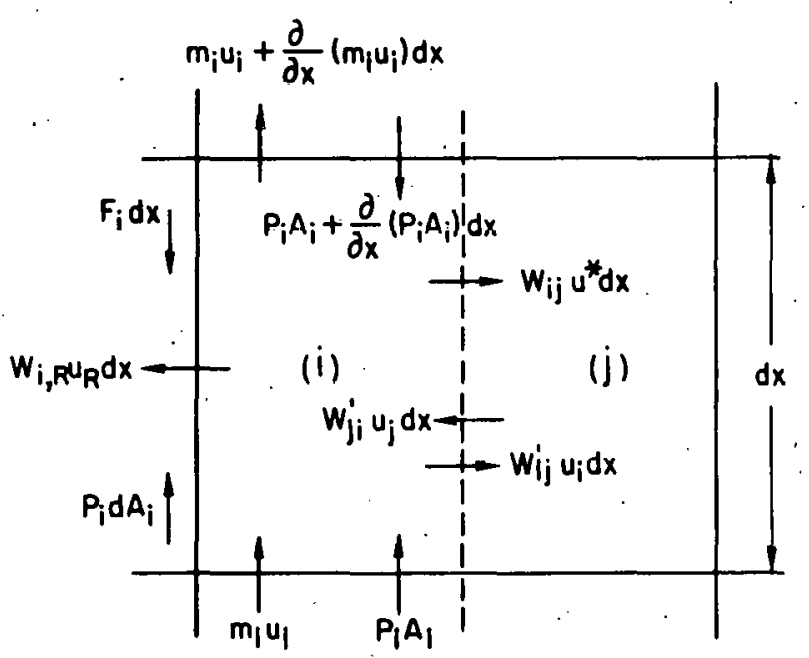

The choice of $u^{*}$, the effective axial velocity carried by the diversion crossflow, must presently be assumed because there is insufficient data to define it accurately. Fortunately, various assumptions of $u^{*}$ have been found to cause only small to moderate changes in the solutions for subchannel flow. In the present study, $u^{*}$ was assumed to be the same as $u_{i}$, the axial velocity of the coolant in the donor subchannel. For a leakage flow, the effective axial velocity $u_{R}$ was also assumed to be the same as $u_{i}$. 
APPENDIX $C$

Material Properties for Thermal Stress Analysis of a Subassembly Duct

Since there is a relatively. large uncertainty in the mechanical properties of the subassembly duct, particularly at high irradiation levels, they are tabulated here for reference.

Table C.I. Properties of Austenitic Steels 304 and 316 (From ASME Boiler and. Pressure Vessel Code, Sect. III)

\begin{tabular}{|c|c|c|c|c|}
\hline $\begin{array}{c}\text { Temp, } \\
{ }^{\circ} \mathrm{F}\end{array}$ & $\begin{array}{l}\text { Yield Stress oy } \\
\text { of. } 304 \text { SS, ksi }\end{array}$ & $\begin{array}{l}\text { Yield Stress } \sigma y \\
\text { of } 316 \mathrm{SS}, \mathrm{ksi}\end{array}$ & $\begin{array}{l}\text { Coefficient of } \\
\text { Therma } 1 \text { Expansion } \\
(\alpha), 10^{-6} \text { in./in. } /^{\circ} \mathrm{F}\end{array}$ & $\begin{array}{l}\text { Modulus of } \\
\text { Elasticity } \\
(E), 10^{3} \mathrm{ksi}\end{array}$ \\
\hline 100 & 30.0 & 30.0 & 9.16 & 28.1 \\
\hline 200 & 25.0 & 25.8 & 9.34 & 27.7 \\
\hline 300 & 22.5 & 23.3 & 9.47 & 27.1 \\
\hline 400 & 20.7 & 21.4 & 9.59 & 26.6 \\
\hline 500 & 19.4 & 19.9 & 9.70 & 26.1 \\
\hline 600 & 18.2 & 18.8 & 9.82 & 25.4 \\
\hline 700 & . $\quad 17.7$ & 18.1 & 9.93 & 24.8 \\
\hline 800 & 16.8 & 17.6 & 10.05 & 24.1 \\
\hline
\end{tabular}

Table C.II. Properties of Austenitic Steels at High Temperature (From HEDL-TME 71-32)

\begin{tabular}{|c|c|c|c|c|}
\hline$\underset{\substack{\text { Temp } \\
{ }^{\circ}}}{ }$ & $\begin{array}{l}\text { Coefficient of } \\
\text { Thermal Expansion } \\
(\alpha), 10^{-6} \text { in. } / \text { in. } /^{\circ} \mathrm{F}\end{array}$ & $\begin{array}{l}\text { Modulus of } \\
\text { Elasticity } \\
(E), 10^{3} \mathrm{ksi}\end{array}$ & $\begin{array}{c}\text { Yield Stress oy } \\
\text { of } 304 \text { sS } \\
\text { (Unirradiated) } \\
\text { ksi }\end{array}$ & $\begin{array}{l}\text { Yield Stress oy } \\
\text { of } 316 \text { SS } \\
\text { (Unirradiated), } \\
\text { ksi }\end{array}$ \\
\hline 600 & 9.83 & 25.4 & 18.2 & 18.9 \\
\hline 700 & 9.95 & 24.7 & 17.5 & 18.0 \\
\hline 800 & 10.07 & 24.1 & 17.0 & 17.4 \\
\hline 900 & 10.19 & 23.4 & 16.3 & 17.1 \\
\hline 1000 & 10.30 & 22.6 & 15.6 & 17.0 \\
\hline 1100 & 10.40 & $21.8^{\circ}$ & 15.0 & 16.6 \\
\hline 1200 & 10.46 & 20.9 & 14.4 & 16.1 \\
\hline 1300 & 10.53 & 20.0 & 13.4 & 15.4 \\
\hline
\end{tabular}


Table C.III. Properties of Type 316 Cold-worked Stainless Stee1 After Irradiationa (From BMI-1900)

\begin{tabular}{ccc}
$\begin{array}{c}\text { Test Temp, } \\
{ }^{\mathrm{F}}\end{array}$ & $\begin{array}{c}\text { Yield Strength, } \\
\mathrm{ksi}\end{array}$ & $\begin{array}{c}\text { Total Elongation, } \\
\%\end{array}$ \\
\hline 600 & 116 & \\
700 & 109 & \\
800 & 103 & $8.5-19.5$ \\
900 & 95 & \\
1000 & 85 & \\
1100 & 68 & \\
1200 & 44 & \\
1300 & 38 & \\
\hline
\end{tabular}

a Irradiated at $482=662^{\circ} \mathrm{F}$ to total neutron fluence of $3.6 \times 10^{22} \mathrm{n} / \mathrm{cm}^{2}, 15 \%$ cold work:

Table C.IV. Properties of Type 316 Cold-worked Stainless Steel After Irradiationa (From GEAP-10062)

\begin{tabular}{ccc}
$\begin{array}{c}\text { Test Temp, } \\
0\end{array}$ & $\begin{array}{c}0.2 \% \text { offset } \\
\text { Yicld Strength, ksi }\end{array}$ & \multicolumn{2}{c}{$\begin{array}{c}\text { Total Elongation, } \\
\%\end{array}$} \\
\hline 932 & 94 & 11 \\
1112 & 56 & 19 \\
1202 & 44 & 18 \\
1292 & 40 & 11 \\
\hline
\end{tabular}

a Irradiated al $350^{\circ} \mathrm{C}\left(662^{\circ} \mathrm{F}\right)$ to $5 \times 10^{22} \mathrm{n} / \mathrm{cm}^{2}$ total; $17 \%$ prestrained. 


\section{ACKNOWLEDGMENTS}

We would like to thank the staff members of Argonne National Laboratory, Hanford Engineering Development Laboratory, Westinghouse Advanced Reactors Division, and the Energy Research and Development Administration, who provided many helpful comments and suggestions during the preparation of this work. In particular, we would like to recognize the efforts of D. H. Lennox, J. F. Marchaterre, R. H. Sevy, S. H. Fistedis, and A. J. Goldman, all of ANL, for their review and comments on the early draft report. Finally, we would also like to acknowledge the helpful encouragement of B. D. LaMar. 


\section{REFERENCES}

1. R. M. Crawford et al., The Safety Consequences of Local Initiating Events in an LMFBR, Argonne National Laboratory (to be published).

2. W. W. Marr et al., Analytical Investigation of Certain Aspects of LMFBR Subassembly Failure Propagation, Argonne National Laboratory (to be published).

3. A. M. Judd and W. R. Bohl, Argonne National Laboratory, persunal communication (Aug 1971).

4. FFTF Safety Testing Program, Vol. I: Safety Assurance Summary, HEDL-TME-71-150 (1972).

5. Report on Fuel Melting Irlcident in the Errwicu Fermi Atomic Fower Plant on October 5, 1966, APDA-233 (Dec 15, 1968).

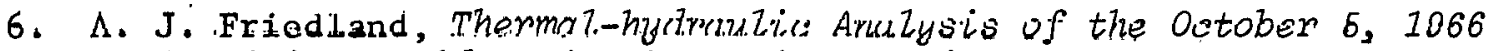
Fuel Melting Incident in the Erraico Fermi Reactor, APDA-IA-5

(July 1969).

7. Fast Flux Test Facility System Design Description for Reactor System, SDD-31, Rev. 1 (May 1972).

8. R. D. Coffield and P. L. Wattelet, An Analytical Evaluation of Fue Failure Propagation for the Fast Flux Test Facility, WARD-AT (45-1)2171-7 (Nov 1970).

9. D. R. Pedersen et al., Evaluation of Wrapper-Can Meltthrough for LMFBR Fuel Subassemblies, I'rans. Am. Nuc1. Soc., 15(2), 817 (1972).

10. L. M. McWethy, P. R. Pluta, and D. B. Sherer, Editors, Core Design Development Needs in Relation to Fuel Failure Propagation, Sodium Boiling and Clad/Fuel-Sodium Thermal Interaction, GEAP-13639-2 (Oct 1970).

11. T. B. McCal1, Updated FFTF Duct Pressure Response Analysis (Supplement to FS-171), Advanced Rediluis Division, Westinghouoc Electric Corporation (Feb 1973).

12. B. 0. Borgartz and G. R. Warren, The Strength of a PFR-type Fue Z Subassembly Wrapper Subjected to an. Internal Exp Losion, UKAEA Internal Document SAFEX/P71 (1966).

13. B. L. Boers, Explosive Technique for Pressure Pulse Testing of Reactor Components, Trans. Am. Nucl. Soc., 12(2), 828 (1969).

14. H. K. Fauske et al., Argonne National Laboratory, personal communication (Sept 1974).

15. J. M. Kennedy, Nonlinear Dynamic Response of Reactor Core Subassemblies, ANL-8065 (Jan 1974). 
16. J. M. Kennedy, "Dynamic Response of Core Subassemblies," Reactor Development Program Progress Report for March 1973, ANL-RDP-15, p. 9.58 .

17. J. M. Kennedy, Summary of ANL Results on the Analysis of EFTF Hexcan Response to a Local MFCI, May 9, 1973, in letter from W. R. Simmons (ANL) to R. E. Peterson (HEDL), May 11, 1973.

18. L. M. McWethy, Editor, An Analytical Evaluation of the Consequences of a Hypothetical Instantaneous Loss of Coolant Flow to a Fast Flux Test Facility Driver Fuel Assembly, GEAP-10059 (July 1969).

19. R. W. Keaten, $L M F B R$ Demonstration Plant Safety Analysis Surmaxy, AI-70-79, (Nov 1970).

20. J. C. Hesson et al., Postaccident Heat Removal in LMFBRs: In-vessel C'onsiderations, ANL-7859 (Sept 1971).

21. J. M. Kennedy et al., Potential Failure of a Hexcan Wrapper Due to Thermal Stress Resulting from Nonuniform. Temperature Distributions, Trans. Am. Nucl. Soc., 15(2), 852 (1972).

22. J. I. Parcel and R. B. Moorman, Analysis of Statically Intermediate Structures, 5, John Wiley and Sons (1955).

23. ASME Boiler and Pressure Vessel Code, Section III, Nuclear Power Plant Components (1971).

24. A. M. Freudenthal, On Inelastic Thermal Stresses in Flight Structures, J. Aeronautical Sci., pp. 772-778 (Nov 1954).

25. J. G. Conner and S. W. Porembka, A Compendium of Properties and Characteristics for Selected LMFBR Cladding Material, BME-1900 (May 1968).

26. F. A. Comprelli et.al., Mechanical Properties of Irradiated Type-304 and Type-316 Stainless Steel in Fast Reactors, GEAP-10062 (June 1969).

27. Liquid Metal Breeder Reactor Materials Handbook, HEDL-TME 71-32 (June 1971).

28. D. S. Rowe, An Improved Mathematical Model for Transient Subchannel Analysis of Rod Bundle Nuclear Fuel Elements, ASME Paper 72-WA/HT-49 (1972). 